De:

Enviado el:

Para:

CC:

Asunto: eesserver@eesmail.elsevier.com en nombre de José Cruz <eesserver@eesmail.elsevier.com> dimarts, 19 / de novembre / 2019 21:49 José María Carmona Pérez; jmcarmonabcn@gmail.com bparker@uoguelph.ca; Jofre Herrero Ferran; Diana Puigserver Cuerda Your Submission

Ms. Ref. No.: STOTEN-D-18-07872R2

Title: Natural attenuation of pools and plumes of carbon tetrachloride and chloroform in the transition zone to bottom aquitards and the microorganisms involved in their degradation Journal: Science of the Total Environment

Dear Dr. Carmona,

I am pleased to inform you that your paper "Natural attenuation of pools and plumes of carbon tetrachloride and chloroform in the transition zone to bottom aquitards and the microorganisms involved in their degradation" has been accepted for publication in STOTEN and forwarded to the publishers.

Why not submit your tailored methods to MethodsX? The new open access journal publishes the tweaks you make to methods without the article padding, so you can get the credit for the time and effort you have put into making a method work for you. www.elsevier.com/locate/methodsX

Your accepted manuscript will now be transferred to our production department and work will begin on creation of the proof. If we need any additional information to create the proof, we will let you know. If not, you will be contacted again in the next few days with a request to approve the proof and to complete a number of online forms that are required for publication.

For any production related questions please contact Pallavi Das(Journal Manager) at j.scitotenv@elsevier.com. There is no need to contact the editors.

Thank you for giving us the opportunity to review your article.

Sincerely,

José Virgílio Cruz, Ph.D.

Associate Editor

Science of the Total Environment

Comments from the Editor:

For further assistance, please visit our customer support site at http://help.elsevier.com/app/answers/list/p/7923. Here you can search for solutions on a range of topics, find answers to frequently asked questions and learn more about EES via interactive tutorials. You will also find our 24/7 support contact details should you need any further assistance from one of our customer support representatives. 
1

2 3 4

1 Natural attenuation of pools and plumes of carbon tetrachloride and chloroform

2 in the transition zone to bottom aquitards and the microorganisms involved in 3 their degradation 


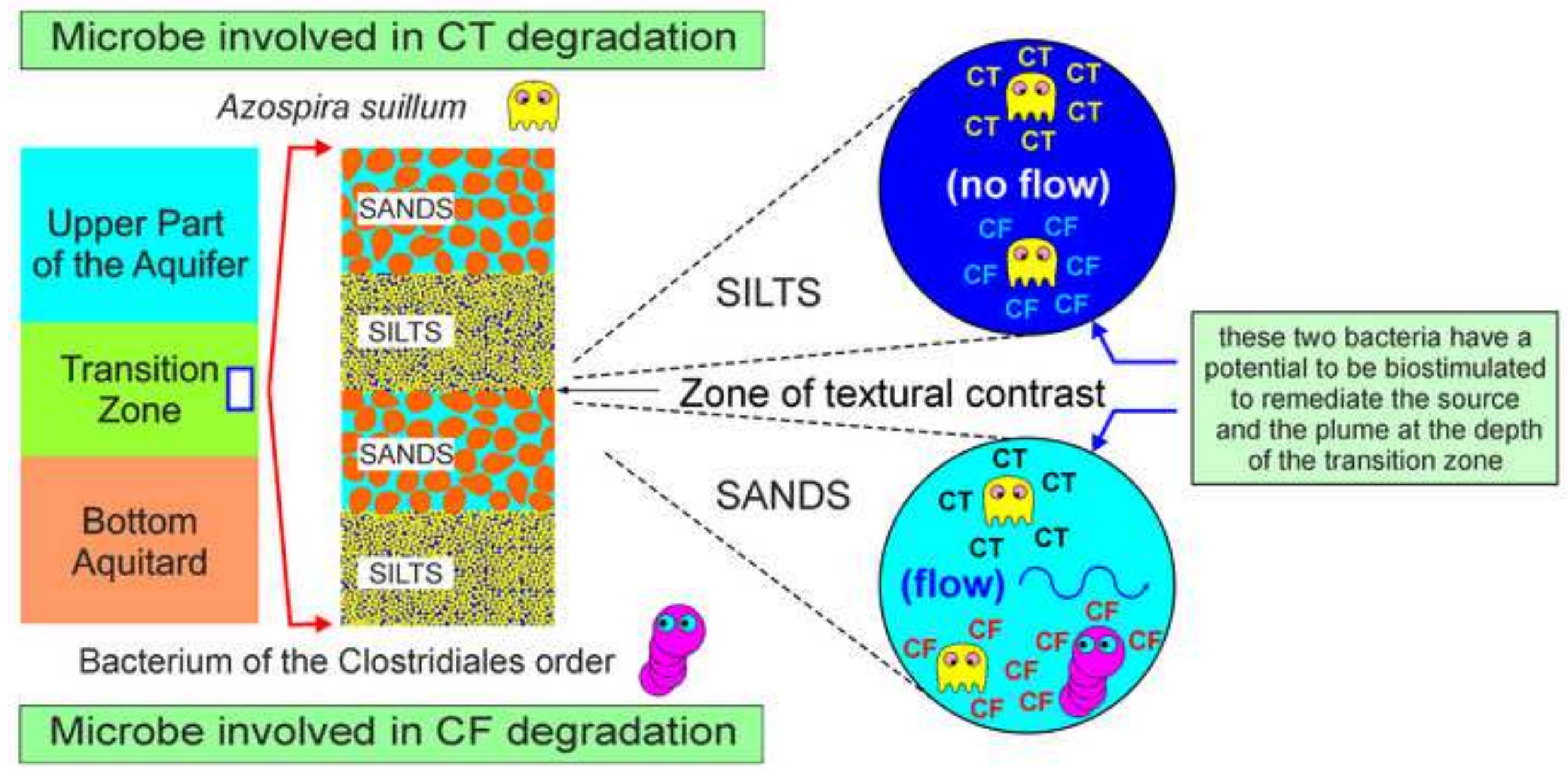


${ }^{*}$ Highlights (for review : 3 to 5 bullet points (maximum 85 characters including spaces per bullet point)

- Pools of chlorinated solvents in the transition zone could be remediated

- Dominant redox conditions and isotope approaches allow to identify dechlorination

- Microorganisms involved in dechlorination were identified at field scale

- Azospira suillum led to a more effective dechlorination in the transition zone

- Biostimulation of these microorganisms could be a plausible remediation strategy 
Supplementary material for on-line publication only
Click here to download Sunnlementary material for

Click here to download Supplementary material for on-line publication only: Supplementary Data (R2).docx

(1) 


\section{Declaration of interests}

$\bigotimes$ The authors declare that they have no known competing financial interests or personal relationships that could have appeared to influence the work reported in this paper.

$\square$ The authors declare the following financial interests/personal relationships which may be considered as potential competing interests:

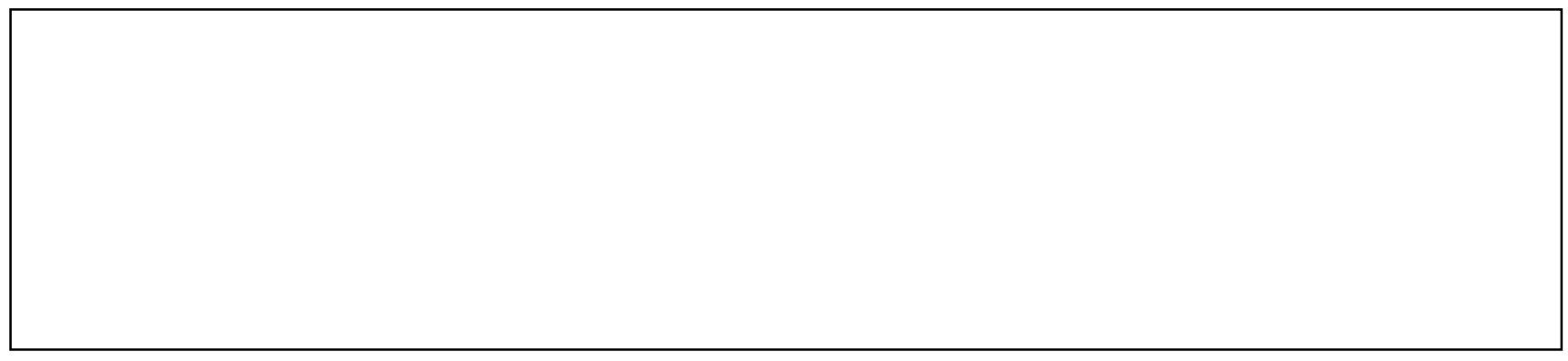


1 Natural attenuation of pools and plumes of carbon tetrachloride and chloroform

2 in the transition zone to bottom aquitards and the microorganisms involved in their degradation

4

5 Diana Puigserver ${ }^{\mathrm{a}}$, Jofre Herrero ${ }^{\mathrm{b}}$, Beth L. Parker ${ }^{\mathrm{c}}$ and José M. Carmona $\mathrm{d}^{*}$

$8 \quad{ }^{a}$ Dept. of Mineralogy, Petrology and Applied Geology. Faculty of Earth Sciences.

9 University of Barcelona. C/ Martí i Franquès, s/n. E-08028 Barcelona (Spain).

10 puigserverdiana@ub.edu

$11{ }^{b}$ Dept. of Mineralogy, Petrology and Applied Geology. Faculty of Earth Sciences.

12 University of Barcelona. C/ Martí i Franquès, s/n. E-08028 Barcelona (Spain).

13 jofreherreroferran@ub.edu

$14{ }^{c}$ School of Engineering, University of Guelph 50, Stone Road East, Guelph, N1G 2W1

15 (Ontario, Canada).bparker@uoguelph.ca

$16{ }^{d}$ Dept. of Mineralogy, Petrology and Applied Geology. Faculty of Earth Sciences.

17 University of Barcelona. C/ Martí i Franquès, s/n. E-08028 Barcelona (Spain).

18 jmcarmona@ub.edu

19

20 * Corresponding author 
23 In the transition zone between aquifers and aquitards, DNAPL pools of carbon

24 tetrachloride and chloroform accumulate because of heterogeneity in this zone.

25 Natural attenuation occur at pools and plumes, indicating that remediation might be possible. The aims of the study were: i) to assess the role of heterogeneity in the natural attenuation of these compounds, ii) determine degradation processes within this zone, and iii) identify dechlorinating microorganisms. For this, groundwater concentrations, redox-sensitive parameters, CSIA isotopic and DGGE molecular techniques were used. The main findings at depth of the transition zone were: (1) The important key control played by heterogeneity on natural attenuation of contaminants. (2) Heterogeneity caused the highly anoxic environment and dominant sulfate-reducing conditions, which accounts for more efficient natural attenuation. (3) heterogeneity also explains that the transition zone constitutes an ecotone. (4) The bacteria size exclusion is governed by the pore throat threshold and determines the penetration of dechlorinating microorganisms into the finest sediments, which is relevant, since it implies the need to verify whether microorganisms proposed for bioremediation can penetrate these materials

(5) Reductive dechlorination caused the natural attenuation of contaminants in groundwater and porewater of fine sediments. In the case of carbon tetrachloride, it was an abiotic process biogenically mediated by $A$. suillum, a bacterium capable of penetrating the finest sediments. In the case of chloroform, it was a biotic process performed by a Clostridiales bacterium, which is unable to penetrate the finest materials. (6) Both microorganisms have potential to be biostimulated to dechlorinate contaminants in the source and the plume in the transition zone. These outcomes are 
47 particularly relevant given the longevity of DNAPL sources and have considerable environmental implications as many supply wells in industrial areas exploit aquifers contaminated by chlorinated solvents emerging from DNAPL pools accumulated on the low-conductivity layers in transition zones.

\section{Keywords}

geological and textural heterogeneity in the transition zone; carbon tetrachloride; chloroform; natural attenuation; reductive dechlorination; Azospira suillum

\section{Introduction}

Carbon tetrachloride (CT) and chloroform (CF) are chlorinated solvents that belong to the group of dense non-aqueous phase liquids (DNAPLs). Together with dichloromethane (DCM) and chloromethane (CM), they are known as chloromethanes.

60 CT and CF have been widely used as precursors of refrigerants (Xiao et al., 2000), and 61 are pollutants harmful to the ozone layer (Fraser et al., 2014), ecosystems, and human and animal health, as they are toxic and carcinogenic. As other chlorinated solvents, CT and CF DNAPLs and plumes are often found in industrial areas that have been subjected to strong anthropic pressure.

65 Chlorinated solvents can last in the environment from decades to hundreds of years as

66 a result of: (1) their low solubility as a free or residual phase; (2) their low natural

67 attenuation (NA) rates when redox conditions are not sufficiently anoxic; (3) the

68 different phases in which they can be partitioned (Pankow and Cherry, 1996); and (4)

69 the portion of them that penetrate through molecular diffusion into the porewater of fine sediments (PWFS), as described in Parker et al. (2004). They cause considerable pollution episodes in groundwater (Mackay and Cherry, 1989; Cohen and Mercer, 
1993; Pankow and Cherry, 1996). Their distribution in the subsurface is quite complex due to geological heterogeneity, which determines not only their distribution as

DNAPLs at the source but also the morphology of the emanating plume (Imhoff et al., 1994; Farthing et al., 2012). In the free phase, they migrate vertically through the most permeable formations, leaving a trail of immobile residual DNAPL that partially occupies the porosity at saturations below the residual saturation value in granular media (Hartog et al. 2010; ITRC, 2015; Fetter et al., 2017). This trail can be progressively dissolved and incorporated into the groundwater flow, while the free phase tends to accumulate as pools at different depths on layers of low hydraulic conductivity (Rivett et al., 2014) and at the bottom of the aquifer (Pankow and Cherry, 1996; Luciano et al., 2010; Fjordbøge et al., 2017; Einarson et al., 2018), occupying a large portion of pores (ITRC, 2015) and making hydraulic conductivity decrease at the source (Fetter et al., 2017).

This pattern is especially noteworthy in cases where a transition zone to a bottom aquitard exists in the lowermost part of an aquifer. In this zone, an intrinsically huge geological heterogeneity occurs because of the presence of numerous interstratified silty-clay levels between sands (Puigserver et al., 2013). This heterogeneity results in a great variability in hydraulic conductivity, and globally, in a whole low value of this parameter, which results in a low groundwater velocity and a minor supply of dissolved oxygen (DO). The low hydraulic conductivity reaches an even lower value because of the large percentage of porosity occupied by DNAPL when the source is in the transition zone. In this scenario, the subsequent lower velocity leads to a minor DO supply and to lesser groundwater flushing and dissolution rate at the source, which accounts for the greater longevity of sources and plumes in transition zones compared with other more conductive depths in the aquifer (Puigserver et al., 2016a, b). The accumulation of DNAPL pools in the transition zone has significant environmental 
implications as many supply wells in the world exploit aquifers that, from the geological point of view, constitute deposits whose lower parts are transition zones.

Cases have been described in which the high concentrations of CT and CF in the source can harm or partly inhibit microbial dechlorinating activity (Da Lima, and Sleep, 2010). However, these pollutants, like other chlorinated solvents, can be degraded naturally by biotic and abiotic reductive dechlorination under appropriate redox anoxic conditions (Ramsburg et al., 2010) in the source and the plume (Hunkeler et al., 2011; Wanner et. al, 2016). Davis et al. (2003) reported the reductive abiotic dechlorination of CT to form CF in the presence of iron-reduced minerals. Penny et al. (2015) observed that only a minor portion of bacteria from anoxic media were capable of degrading CT in the laboratory. Puigserver et al. (2016c) identified Azospira suillum (formerly Dechlorosoma suillum, Achenbach et al., 2001) in microcosm experiments at laboratory scale with real field samples from the same site as this work and noted the unique presence of this microorganism (and another belonging to the order Clostridiales) when redox conditions became sulfate-reducing and the abiotic reductive dechlorination of CT to CF occurred. These examples corroborate that the assessment of the dominant redox conditions in sources and plumes is crucial to understanding the fate of these pollutants and to evaluate remediation strategies. In the case of the transition zone, the examples suggest that the minor supply of DO and the subsequent occurrence of anoxic conditions favor in situ biotic or abiotic remediation of the source and the plume.

Christensen et al. (2000), in a review on the characterization of the dominant redox conditions in groundwater contaminant plumes, demonstrated that these conditions, which control the biotic and abiotic processes occurring in the environment, could be evaluated according to the relative distribution of contaminants with respect to the redox-sensitive inorganic species together with other parameters and approaches such 
124 as redox potential (Eh), total organic carbon (TOC), and use of the Compound-Specific

125 Isotope Analysis technique (CSIA).

126 The aims of the current study were: i) to assess the role played by geological and

127 textural heterogeneity in the transition zone in the degradation of CT and CF, ii) to

128 determine the degradation processes of these compounds in this zone and evaluate

129 the magnitude of NA processes, and iii) to identify the microorganisms involved in the

130 NA of these compounds. To this end, a site was chosen for the current study where an

131 unconfined aquifer was affected by CT and CF contamination.

\section{$132 \quad 2 . \quad$ Site description}

133 The study site is located in the La Pineda petrochemical complex (Tarragona, Spain,

$134100 \mathrm{~km}$ south of Barcelona), which became active in stages, beginning in 1960. Two

135 main pollutants caused contamination by CT and CF in an unconfined granular aquifer.

136 The pollution was detected in 1996 in one of the plants of the complex, although it is

137 unknown when the contamination first appeared. These compounds were used in

138 refrigerant production (Puigserver et al., 2013) and were stored independently in two

139 tanks. Spillages, which occurred repeatedly, varied in duration and accumulated on the

140 numerous layers of low hydraulic conductivity in the transition zone and on the geologic

141 contact with the bottom aquitard. In addition, superimposed upon this contamination,

142 other contamination episodes occurred in the past, resulting in a complex pattern of

143 contamination characterized by a variety of compounds from different origins (other

144 chloromethanes, chloroethenes, chloroethanes, BTEX, PAHs and metals).

145 Furthermore, agricultural land uses upgradient of the petrochemical complex give rise

146 to groundwater pollution by inorganic co-contaminants, nitrates, and sulfates related to

147 fertilization practices. These electron acceptors migrate with groundwater flow and

148 reach the industrial area, where the contamination by CT and CF exists.

149 A substantial portion of the pollutants penetrated via molecular diffusion into the PWFS

150 (Puigserver et al., 2013). Despite the considerable decrease in the concentrations of 
151 CT and CF in groundwater between 1997 and 2009 (maximum values in 1997 of 771

152 and $19,370 \mu \mathrm{g} / \mathrm{L}$ for CT and CF, respectively; and in 2009 , of 308.2 and $552.1 \mu \mathrm{g} / \mathrm{L}$,

153 respectively), pollution continued to be above the parametric values due to the

154 application of the pump-and-treat remediation system, which reached its limit of

155 effectiveness (Puigserver et al., 2016a).

156 The groundwater monitoring network (Figure 1) consists of 26 conventional

157 piezometers and two multilevel wells (CMT 7 ports, Solinst). Conventional piezometers

158 (with depths ranging from 11 to $20 \mathrm{~m}$, Figure $2 \mathrm{~A}$ ) consist of: 1 ) a first section of blind

159 pipe (i.e., non-screened) reaching depths ranging from 10 to $12 \mathrm{~m}$; 2) a second section

160 of screened pipe that is open from the upper part of the aquifer (UPA) to its lower part,

161 which is a transition zone to a bottom aquitard (TZBA)(see Section 4.1); and 3) a third

162 short section of blind pipe for piezometers deeper than $17 \mathrm{~m}$ (depth where a clayey

163 bottom aquitard exists). The two multilevel wells (S1UB and S2UB) are $220 \mathrm{~m}$

164 downstream of the source and are located $5 \mathrm{~m}$ apart (Figure 1). Port 7, the deepest of

165 the seven ports of S1UB and S2UB, are 12.60 and $12.80 \mathrm{~m}$ deep, respectively. To

166 construct these multilevel wells, boreholes B-S1UB and B-S2UB were drilled (22.00

167 and $16.37 \mathrm{~m}$ deep, respectively) and equipped as multilevel wells. The analysis of the

168 stratigraphic logs of the monitoring network allowed determination of the lithological

169 and textural characteristics of the subsoil in the site area. Moreover, emplacement of

170 the monitoring network allowed the study of variations in groundwater quality.

171 According to the historical evolution of the concentrations of CT and CF along the flow

172 path, there are two sources, including the main source (from conventional piezometer

173 S5-P2 to P7) and a smaller, secondary source detected immediately upstream from P8

174 (Figure 1 and Figure 2A).

$175 \quad 3 . \quad$ Materials and methods

176 The methodological procedures shown in this section were followed to attain the

177 objectives raised in the study (see Section 1). These procedures allow the assessment 
178 of the role of geological and textural heterogeneity in the transition zone in degradation

179 of CT and CF. To define that role, the determination of the dominant redox conditions

180 and the identification of the biogeochemical processes occurring under these

181 conditions were carried out. This was done along the flow and with depth comparing

182 the results in the UPA (a very homogeneous hydrostratigraphic unit) with the TZBA (an

183 extremely heterogeneous unit). For this, the groundwater sampling to analyze redox-

184 sensitive species allowed: i) identifying the dominant redox conditions, ii) verifying if NA

185 of CT and CF was occurring, and iii) if NA was more efficient in the TZBA. The

186 determination of the NA rate of these compounds $(\lambda)$ and the isotopic enrichment factor

$187(\varepsilon)$ allowed quantifying the magnitude of this degradation. The results acquired from the 188 bacterial community analysis, permitted: i) the identification pf the hydrostratigraphic

189 unit where microbial diversity and abundance were greater, and ii) identifying which

190 were the microorganisms involved in degradation of CT and CF. The integration of

191 these results with the previous referring to the biogeochemical processes and redox

192 conditions in which these processes occurred, allowed determining in which

193 hydrostratigraphic unit the dechlorinating microorganisms were more efficient and

194 under what redox conditions they achieved this task.

\subsection{Dominant redox conditions and degradation processes}

196 To assess the dominant redox conditions in the subsurface of the studied site, the 197 guidelines established by Christensen et al. (2000) and subsequently implemented by

198 many other authors (Rotiroti et al., 2018; Weatherill et al., 2018) were followed in the

199 current work. They consist in characterizing the dominant redox processes in

200 groundwater, which allowed identification of the dominant redox conditions under which

201 these processes occurred. These dominant redox conditions determine the redox zone

202 to which the environment is assigned. These redox zones refer to the classical model

203 that, from the thermodynamic point of view, establishes a vertical sequence of the

204 dominant electron acceptors in natural water and sediment systems. In this model, in 
205 descending potential of metabolic energy yield, oxygen, nitrate/nitrite, $\mathrm{Mn}^{4+} / \mathrm{Mn}^{2+}$, $206 \mathrm{Fe}^{3+} / \mathrm{Fe}^{2+}$, sulfate/sulfide, and $\mathrm{CO}_{2} / \mathrm{CH}_{4}$ are the successive oxidizing agents with 207 increasing depth (i.e., with a gradient in redox conditions that varies from completely 208 oxidizing to extremely reducing).

209 Analyses of groundwater samples in conventional piezometers and multilevel wells in

210 the monitoring network allowed the study of the variability of groundwater quality and to

211 determine the dominant redox conditions and degradation processes along the flow

212 path in the transition zone and with depth, respectively. Samples taken in conventional

213 piezometers represent all flow lines crossing the section of screened pipe in the

214 influence area of the sampling pump at the depth to which it is placed. Analytical

215 results are therefore, an integrated value of the mentioned flow lines. In contrast,

216 groundwater taken in the sampling ports $(4 \mathrm{~cm}$ long) of multilevel wells allowed

217 obtaining greater accuracy in the representation of results with depth. The following

218 parameters and concentrations were determined along the flow path and with depth:

219 (1) temperature, electrical conductivity and $\mathrm{pH}$, which were measured on site when

220 sampling; (2) Eh and DO, which were recorded on site, as well as other redox-sensitive

221 parameters (TOC, nitrate, nitrite, $\mathrm{Mn}^{2+}, \mathrm{Fe}^{2+}$, and sulfate, which were analyzed in the

222 laboratory); and (3) chloromethanes.

223 In addition, the CSIA technique was applied to the groundwater samples from the same

224 piezometers and wells as a tool to study and characterize the degradation processes of

$225 \mathrm{CT}$ and CF (US EPA, 2008) by determining their isotopic fractionation $\left(\delta^{13} \mathrm{C}\right.$ values).

226 The CSIA technique is a powerful tool in the characterization of the degradation

227 processes of chlorinated solvents (US EPA, 2008). In general, the degradation of a

228 compound more easily affects molecules with light isotopes, resulting in a relative

229 enrichment in molecules with heavy isotopes in the groundwater $\left({ }^{12} \mathrm{C}\right.$ and ${ }^{13} \mathrm{C}$,

230 respectively in the case of CT and CF). Furthermore, $\delta^{15} \mathrm{~N}$ and $\delta^{18} \mathrm{O}$ values of nitrate,

231 and $\delta^{34} S$ and $\delta^{18} \mathrm{O}$ of sulfate were also used to identify denitrifying and sulfate-reducing 
232 processes (the reduction potential of these inorganic compounds is greater than that of

233 CT and CF, and therefore the degradation of the last two compounds is partially

234 inhibited).

235 The $\lambda$ and $\varepsilon$ values to evaluate the extent of degradation of CT between two

236 conventional wells A and B separated from each other by a distance $d$ (in meters) were

237 calculated along the flow path in the source area and along the centerline of the plume.

238 The equation $\lambda=\ln (\mathrm{f}) / \mathrm{d}$ (Hunkeler et al., 2008) was used to calculate the rate of

239 attenuation $\left(\lambda\right.$, in $\left.\mathrm{m}^{-1}\right)$. In this equation, $f$ is the remaining fraction of the contaminant in

240 well $B$ (located downgradient from well $A$ ), therefore, $f=C_{B} / C_{A}$, where $C_{A}$ is the

241 concentration in well $A$ and $C_{B}$ is the concentration in well $B$. In turn, the isotope

242 enrichment in ${ }^{3} \mathrm{C}(\varepsilon$, in \%o) was calculated using the following equation: $\varepsilon=(\alpha-1) \cdot 1000$

243 (Hunkeler et al., 2008), where $\alpha=\left(1000+\delta^{13} C_{A}\right) /\left(1000+\delta^{13} C_{B}\right)$ is the isotope

244 fractionation factor of ${ }^{3} \mathrm{C}$, in which subscripts $A$ and $B$ refer to wells $A$ and $B$, and $\delta^{13} C$

245 refers to CT. These two equations were also used to analyze the rate of attenuation

246 and the enrichment factor of CT with depth in the two multilevel wells in the plume. In

247 this case, the maximum concentration at the source (in conventional piezometer P7,

248 Figure 4A.C) was taken as $C_{A}$, whereas $C_{B}$ in the UPA and TZBA (Figure 2A) were the

249 average concentrations in the sampling ports of the multilevel wells (1, 3 and 4 for the

250 UPA and 5, 6 and 7 for the TZBA). The values of $\lambda$ and $\varepsilon$ for the case of CF were also

251 calculated using the previous equations (with $\delta^{13} \mathrm{C}$ referred to $\mathrm{CF}$ ).

252 The $\lambda$ and $\varepsilon$ values of nitrate and sulfate between two conventional wells were also

253 calculated along the flow path in the source area and along the centerline of the plume,

254 as well as from the source area to the sampling ports of multilevel wells in the UPA and

255 TZBA. In all these cases, the background concentration of these co-contaminants in

256 the zone upgradient of the main source of CT and CF were taken as $C_{A}$. The $\delta^{15} \mathrm{~N}$ and

$257 \delta^{34} S$ values were used to calculate the $\varepsilon$ value of nitrate and sulfate, respectively.

\subsubsection{Sampling protocols and procedures}


259 Conventional piezometers in the monitoring network that approximately followed a

260 profile along the centerline of the source and plume (Figure 1 and Figure 2A) were

261 used to sample groundwater from the TZBA. In these piezometers, groundwater was

262 pumped from the depth of the contact TZBA-BA (similar to that of port 7, the deepest of

263 multilevel wells). Multilevel wells S1UB and S2UB were used to sample groundwater

264 with depth in the plume (ports 1 to 4 at the UPA, and ports 5 to 7 at the TZBA). In

265 addition, groundwater and fine sediments were sampled in wells and boreholes to

266 determine dissolved TOC contents and particulate organic matter, respectively,

267 upgradient of the petrochemical complex at the depth of the TZBA. Groundwater

268 samples were taken using an Eijkelkamp peristaltic pump and an Integra Solinst

269 Bladder pump (Georgetown, Ontario, Canada) depending on the depth of the

270 piezometers and multilevel wells. A flow cell (Solinst) was used to ensure intact redox

271 conditions during the purging and sampling operations and when measuring

272 physicochemical parameters on site. Aqueous samples were collected in $100-\mathrm{mL}$ VOC

273 glass serum bottles (Supelco Analytical) for concentration analyses and in 120-mL

274 amber screw-cap bottles (Supelco Analytical) for carbon isotope analyses. Sodium

275 azide $\left(\mathrm{N}_{3} \mathrm{Na}\right.$; Fluka, Tres Cantos-Madrid, Spain) was added to the groundwater

276 samples immediately upon collection to inhibit bacterial activity following procedures

277 reported by Trevors (1996). For TOC concentrations, 120-mL amber screw-cap bottles

278 (Supelco Analytical) were used (analytical quality hydrochloric acid, Merck, was used to

279 acidulate these samples up to a $\mathrm{pH}$ of 3). The groundwater samples for nitrate and

280 sulfate analyses were collected in $150-\mathrm{mL}$ translucent plastic bottles, and Pyrex glass

281 bottles were used for $\delta^{15} \mathrm{~N}_{\text {nitrate, }}, \delta^{18} \mathrm{O}_{\text {nitrate, }} \delta^{34} \mathrm{~S}_{\text {sulfate, and }} \delta^{18} \mathrm{O}_{\text {sulfate }}$ analyses.

282 Groundwater samples for $\mathrm{Mn}$ and Fe were collected in 14-mL transparent plastic vials.

283 The samples were conserved at $4{ }^{\circ} \mathrm{C}$. The sampling and conservation protocols

284 indicated in Puls and Barcelona (1996) and Johnston (2006) were used during

285 transport and at the laboratory. The field blanks that were taken (blanks of

286 instrumentation, conservation reagents, and transportation to laboratory) are indicated, 
287 among other aspects, in these protocols. In addition to these blanks, each sample of

288 groundwater was taken in duplicate to have a good control of the analytical results in

289 the laboratory.

290 PWFS is water fundamentally immobile and enclosed inside the tiny pores of fine

291 sediments of the formation (silty sands, silts and clays, and clayey and silty matrices of

292 coarse sediment). PWFS and the corresponding fine sediment fraction were sampled

293 at different depths from boreholes B-S1UB and B-S2UB (drilling procedures and core

294 recovering protocols are described in Puigserver et al., 2013). The purpose of these

295 samples was to analyze the diversity and abundance of microbial communities and to

296 identify the microorganisms involved in CT and CF degradation in the PWFS.

\section{$297 \quad$ 3.1.2 Laboratory analytical methods, techniques and instrumentation}

298 The samples were analyzed at laboratories of the Scientific and Technological Centers

299 of Barcelona University. These laboratories implement a quality management system

300 based on the ISO 9001:2015 standard. This implies that a strict laboratory control

301 sampling protocol was followed, which included the use of laboratory blanks and

302 standard reference materials.

303 As a quality control of the laboratory analytical results, the absolute relative percent

304 difference (RPD\%) calculation between the field duplicates was used as a measure for 305 evaluation of the precision of these results. For this calculation, the absolute value of

306 the difference between the analytical results of the two duplicates is divided by the

307 absolute value of the average of the two results. The value obtained is expressed as a

308 percentage multiplying it by 100 :

$$
\mathrm{RPD} \%=[|\mathrm{D} 1-\mathrm{D} 2| /((|\mathrm{D} 1+\mathrm{D} 2|) / 2)] \times 100
$$

310 where $|\mathrm{D} 1-\mathrm{D} 2|$ and $|\mathrm{D} 1+\mathrm{D} 2|$ are the absolute values of the difference and

311 summation of the duplicate sample results, respectively. 
312 The RPD\% values for CT concentrations between 1.7 and $0.2 \mu \mathrm{mol} / \mathrm{L}$ varied from 4.57

313 to $13.03 \%$, respectively; and for concentrations between 0.2 and $0.014 \mu \mathrm{mol} / \mathrm{L}$, it varied

314 from $13.03 \%$ to $15.48 \%$. In the case of CF, the RPD\% values for concentrations

315 between 10.7 and $0.3 \mu \mathrm{mol} / \mathrm{L}$ varied from 2.67 to $4.77 \%$, respectively; and for

316 concentrations between 0.3 and $0.02 \mu \mathrm{mol} / \mathrm{L}$ varied from 4.77 to $15.01 \%$. For DCM

317 between 0.3 and $0.042 \mu \mathrm{mol} / \mathrm{L}$ varied from 4.69 to $11.98 \%$, respectively; and between

3180.042 and $0.021 \mu \mathrm{mol} / \mathrm{L}$ varied from 11.98 to $13.10 \%$. For $\mathrm{CM}$ between 1.0 and 0.13

$319 \mu \mathrm{mol} / \mathrm{L}$ varied from 6.35 to $12.27 \%$, respectively; and between 0.13 and $0.033 \mu \mathrm{mol} / \mathrm{L}$

320 varied from 12.27 to $15.74 \%$.

321 As regards the ${ }^{13} \mathrm{C}$ isotopic composition of chloromethanes, only the RPD\% values for

322 CT and CF were calculated, given the very low concentrations of DCM and CM. The

$323 \delta^{13} \mathrm{C}_{\mathrm{C}}$ maximum, average, and minimum RPD\% values, were $1.41,0.92$, and $0.28 \%$,

324 respectively. In the case of $\delta^{13} \mathrm{C}_{\mathrm{CF}}$, those values were $1.29,0.91$, and $0.27 \%$,

325 respectively.

326 The RPD\% values for $\delta^{15} \mathrm{~N}_{\text {Nitrate }}$ and $\delta^{18} \mathrm{O}_{\text {Nitrate, and for }} \delta^{34} \mathrm{~S}_{\text {Sulfate }}$ and $\delta^{18} \mathrm{O}_{\text {Sulfate, }}$ were

327 also calculated. The $\delta^{15} \mathrm{~N}_{\text {Nitrate }}$ maximum, average, and minimum RPD\% values were

$3282.63,1.20$, and $0.56 \%$, respectively; and for $\delta^{18} \mathrm{O}_{\text {Nitrate, }}$, they were $7.50,2.83$, and

$3290.45 \%$, respectively. The $\delta^{34} S_{\text {Sulfate }}$ maximum, average, and minimum RPD\% values

330 were $4.59,1.78$, and $0.52 \%$, respectively; and for $\delta^{18} \mathrm{O}_{\text {Sulfate }}$, they were $5.01,2.38$, and

$331 \quad 0.56 \%$, respectively.

332 The chloromethanes concentrations were measured using gas chromatography-mass

333 spectrometry (GC-MS). The limits of quantification (LOQ), as a measure of sensitivity

334 of results, were (in $\mu \mathrm{mol} / \mathrm{L}$ ): 0.0075 (CT), 0.0159 (CF), 0.0171 (DCM), and 0.0297

335 (CM).

336 A protocol based on the extraction of VOCs by direct adsorption from the aqueous

337 phase was used to determine the $\delta^{13} \mathrm{C}$ of chloromethanes. The extraction was

338 conducted by inserting an adsorbent fiber (SPME fiber assembly $75 \mathrm{~mm}$ 
carboxen/polydimethylsiloxane (PDMS), Supelco (Madrid, Spain)) into the water

340 sample, which was stored in a 100-mL amber glass bottle (Supelco Analytical) and

341 closed with a silicone septum and agitated for $30 \mathrm{~min}$ to adsorb the chloromethanes.

342 The determination of $\delta^{13} \mathrm{C}$ was performed using gas chromatography-combustion

343 isotope ratio mass spectrometry (GC-CIRMS) following the protocol described in Palau

344 et al. (2007) and using a Delta C Finnigan (an earlier name of Thermo Fisher Scientific,

345 Inc.) MAT IRMS spectrometer (Thermo Fisher Scientific Inc., Waltham, MA, USA).

346 TOC was analyzed using a TOC-5000 TOC analyzer (Shimadzu). The sulfate, nitrate,

347 and nitrite concentrations were analyzed following the EPA 9056 protocol using ion

348 chromatography. The pretreatment protocols used to determine the nitrate and sulfate

349 isotopic compositions were those indicated in Dogramaci et al. (2001) for determining

$350 \quad \delta^{34} S_{\text {sulfate }}$ and $\delta^{18} \mathrm{O}_{\text {sulfate, }}$ and in Silva et al. (2000) and Fukada et al. (2003) for obtaining

$351 \quad \delta^{15} \mathrm{~N}_{\text {nitrate }}$ and $\delta^{18} \mathrm{O}_{\text {nitrate. }}$. The resulting precipitates were analyzed using isotope ratio

352 mass spectrometry (IRMS).

\section{$353 \quad 3.2 \quad$ Bacterial community analysis}

354 To assess the diversity and abundance of microorganisms with depth, in the case of

355 biotic degradation, denaturing gradient gel electrophoresis (DGGE) analyses were

356 conducted in the groundwater samples obtained from ports of the multilevel wells

357 S1UB and S2UB and in the samples of PWFS from fine sediment cores recovered from

358 boreholes B-S1UB and B-S2UB.This technique involves the separation pattern of

359 polymerase chain reaction (PCR)-amplified 16S rDNA gene fragments in

360 polyacrylamide gels with a linearly increasing gradient of denaturants (Muyzer et al.,

361 1993). The number of DGGE bands corresponds to the number of main members in

362 the microbial community. Although ideally, one band on the gel corresponds to one

363 species (Cycoń et al., 2013), and hence, the number of bands is an indicator of the

364 sample's diversity. The relative abundance of a microorganism can be estimated by 
measuring the brightness intensity of its bands relative to the intensity of all the bands

366 in the analyzed samples.

367 The sampling protocols and procedures used to obtain fine sediments from the cores of

368 the boreholes B-S1UB and B-S2UB are described in Puigserver et al. (2013). DGGE electrophoresis of PCR-amplified 16S rRNA genes was run in denaturing acrylamide gels and stained prior to photography following standard methodologies. Unweighted

371 DGGE band data were used to assess the diversity in each groundwater and PWFS

372 sample, i.e., the presence or absence of DGGE bands in each lane sample. Weighted

373 data were used to evaluate the abundance of a microbial community in a lane sample

374 considering the brightness intensity of each band relative to the intensity of bands in all

375 the analyzed samples, including the lanes of two DGGE band markers, denoted as

376 operational taxonomic unit 6 (OTU 6) and 15 (OTU 15) in the current work. These two

377 OTUs correspond to the two microorganisms that Puigserver et al. (2016c) found to be

378 involved in CT and CF degradation ( $A$. suillum and a Clostridiales bacterium,

379 respectively, see Section 1).

380 To identify the presence of these microorganisms at the field scale (i.e. with depth in

381 groundwater from multilevel wells S1UB and S2UB, and in PWFS from boreholes B-

382 S1UB and B-S2UB), results of DGGE analyses were combined with those obtained in

383 a clone library analysis. Detailed information on the microbiological and clone library

384 analysis is described in the Supplementary Data (SD).

\section{$385 \quad 4 . \quad$ Results and discussion}

\section{$386 \quad 4.1 \quad$ Geological and hydrogeological framework}

387 The aquifer is composed of Quaternary prograding alluvial fan deposits, at the base of

388 which, there is a transition zone that corresponds to sheet flood deposits associated

389 with the alluvial fans. Groundwater flows towards the Mediterranean Sea, according to

390 the slight dip of the subsoil layers (Figure 2A) to the southeast. The water table 
oscillates between 5.5 and $9 \mathrm{~m}$ below ground level, with an average maximum water

392 table oscillation of $1.5 \mathrm{~m}$ over the year. The geological cross-section in Figure $2 \mathrm{~A}$

393 shows the non-saturated zone above the water table, which is composed of

394 paleochannels of gravels and sands. This figure also shows the three

395 hydrostratigraphic units defined at this site: (1) the upper part of the aquifer (UPA),

396 which is also dominated by paleochannels of sands and gravels with interbedded

397 layers of sands with fine matrix, although from the geological and textural point of view,

398 this unit is homogeneous as a whole); (2) the lowermost part of the aquifer, which

399 corresponds to the transition zone down to the bottom aquitard (TZBA, $2.30 \mathrm{~m}$

400 thickness), constitutes the sheet floods of the alluvial fans, and is a unit that

401 geologically and texturally is highly heterogeneous, and is composed of numerous

402 interstratified layers of millimeter and centimeter scale, formed by silty-clays between

403 fine to coarse sands and gravels with variable fine matrix content; and (3) the bottom

404 aquitard (BA), which is composed of red clays, at a depth of $14 \mathrm{~m}$.

405 Figure 2B displays the lithological, textural, and hydraulic conductivity differences

406 between the UPA and TZBA (the weighted average hydraulic conductivities at B-S1UB

407 were 160 and $1 \mathrm{~m} / \mathrm{d}$, respectively; and at B-S2UB, 230 and $4 \mathrm{~m} / \mathrm{d}$, respectively).

408 Furthermore, large differences in transmissivity occur between the UPA and the TZBA

409 (5.25 and $590 \mathrm{~m}^{2} / \mathrm{d}$, respectively). These differences in hydraulic conductivity and

410 transmissivity derive from the different degree of geological and textural homogeneity-

411 heterogeneity between both hydrostratigraphic units. The UPA and TZBA maintain their

412 homogenous and heterogeneous character, respectively, throughout the monitored

413 zone, as evidenced by the detailed analysis of stratigraphic logs of boreholes in the

414 monitoring network (Figure 2B). More information on the geological and

415 hydrogeological framework is provided in the SD.

416 


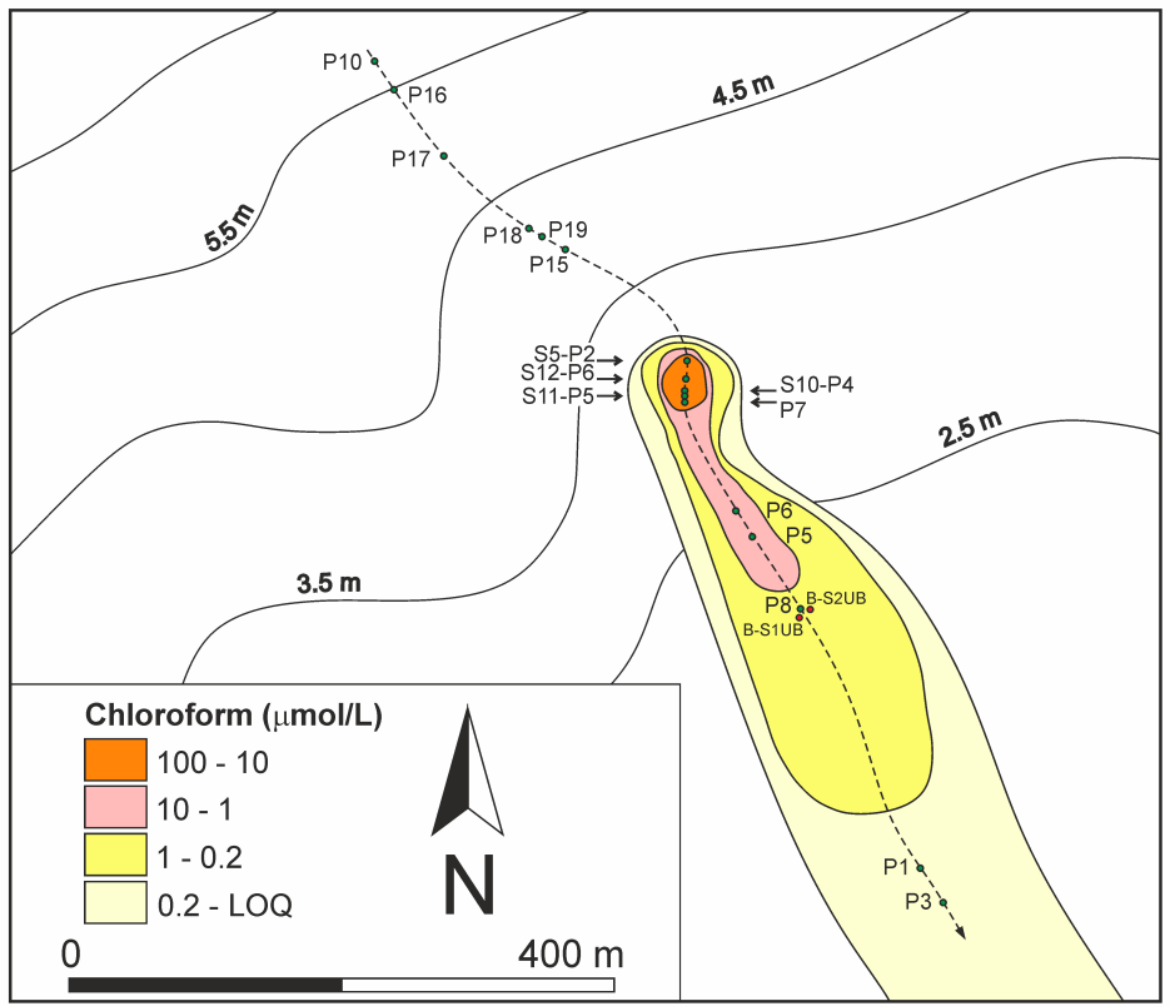

417

418 Figure 1. Water table map (in $m$ above mean sea level) and contaminant CF plume.

419 LOQ: limit of quantification. Dashed line: centerline of the source-plume (with the 420 projection of piezometers that follow this line). B-S1UB and B-S2UB are the boreholes 421 drilled to construct multilevel wells S1UB and S2UB, respectively. 


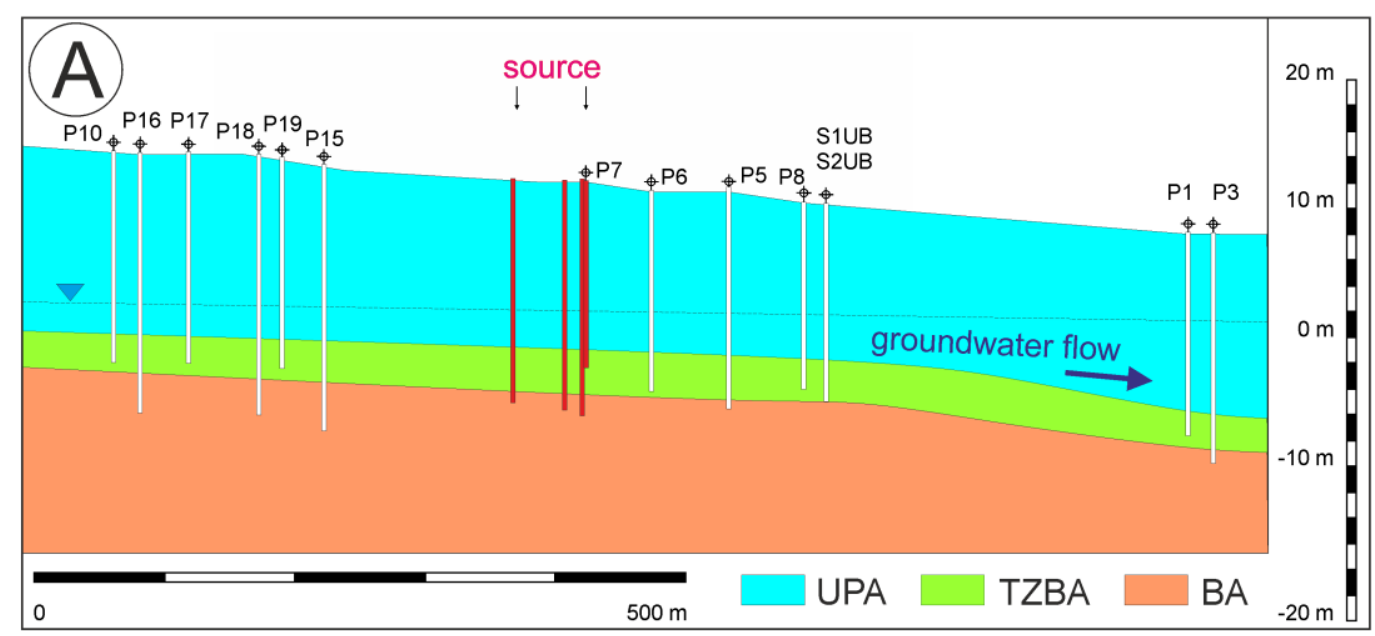

(B)
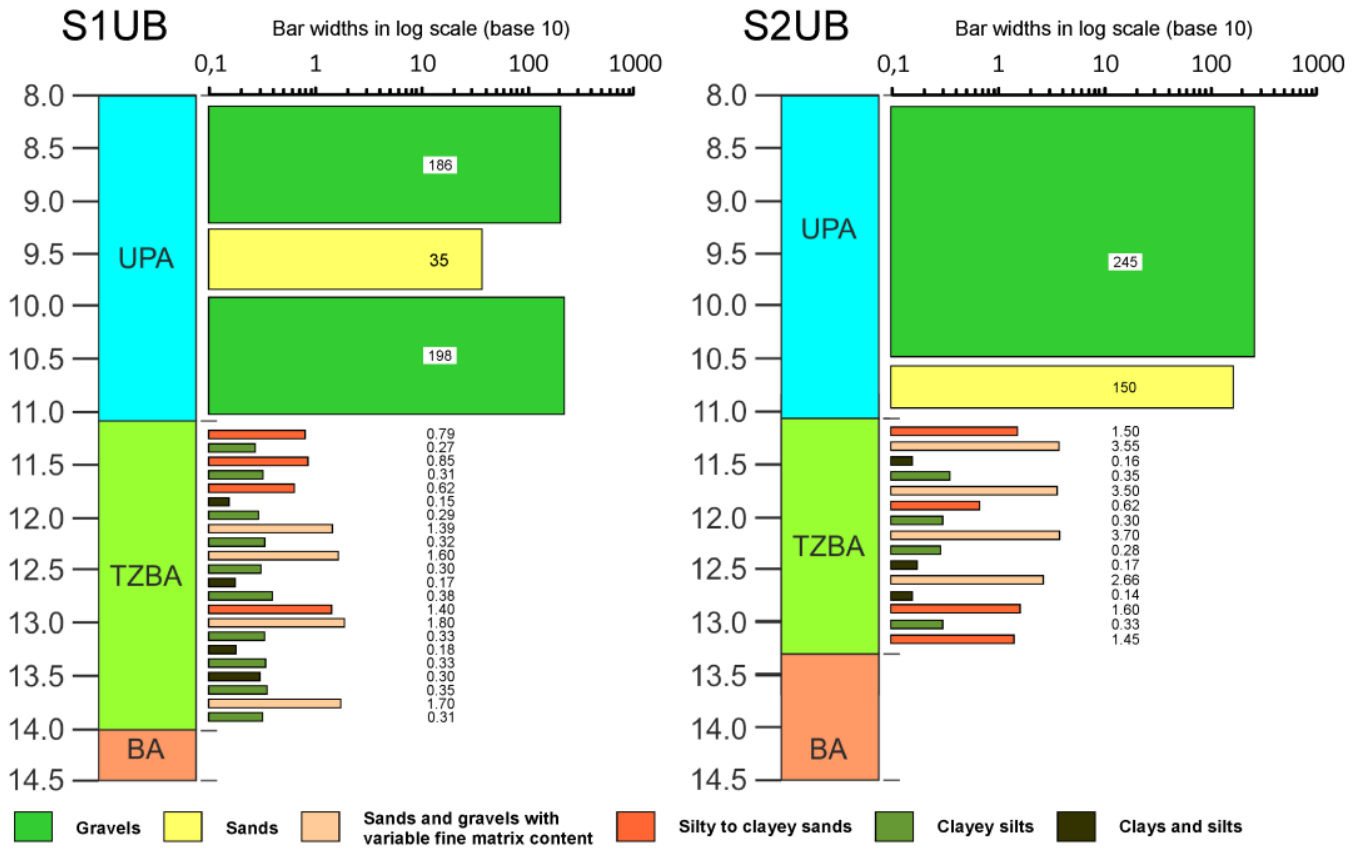

Figure 2. (A) Geological cross-section along the centerline of the plume showing the hydrostratigraphic units defined and piezometers and wells of monitoring network. (B) Variation with depth ( $\mathrm{m}$ below ground) of the lithological and textural characteristics, and hydraulic conductivity (m/day) of the two studied hydrostratigraphic units (UPA and 

the flow path

\subsubsection{Eh values and redox-sensitive parameters and chloromethanes}

434 A summary of the Eh values and concentrations of redox-sensitive parameters (DO, $435 \mathrm{TOC}$, nitrate, nitrite, $\mathrm{Mn}^{2+}, \mathrm{Fe}^{2+}$, and sulfate) in the TZBA along the flow path, from 436 upgradient of the main source to the front of the plume (Figure 1), is presented in

437 Figure 3. This figure shows that the most highly reducing conditions occurred in the 438 area of the main DNAPL source (Eh ranged between -63 and $-134 \mathrm{mV}$, Figure $3 \mathrm{~A}$ ).

439 Various elements converge in the main source area that make redox conditions highly

440 anoxic in this area at the TZBA: i) the intrinsically high geological and textural

441 heterogeneity in the TZBA, which implies a low hydraulic conductivity (see Section 4.1

442 and Figure 2B) and little DO supply with groundwater flow; ii) the fact that a large 443 portion of pores in the UPA and TZBA are occupied by DNAPL at different saturations 444 (ITRC, 2015), leading to a greater decrease in hydraulic conductivity (Fetter, et al., 445 2017) and contributing even more to a decline in the supply of DO; and iii) the 446 consumption of what little DO remains to oxidize the high TOC contents in groundwater 447 (which ranged between 124.9 and $25.2 \mathrm{mg} / \mathrm{L}$, Figure $3 \mathrm{H}$ ) and particulate organic matter 448 in subsurface sediments. The TOC values are consistent with the high organic carbon 449 background associated with the petrochemical activities at the site reported by

450 Puigserver et al. (2013). A non-negligible part of this background is formed by natural 451 dissolved and particulate organic matter, as evidenced by groundwater and fine 452 sediments sampled at the depth of the TZBA upgradient of the petrochemical 453 complex).

454 Although nitrate and sulfate are two co-contaminants that cause diffuse contamination 455 of groundwater across the whole region, their concentrations tended to decrease in the 456 TZBA along the flow path upgradient of the source, with low $\lambda$ and $\varepsilon$ values of 0.00048 and $0.00032 \mathrm{~m}^{-1}$, and -1.45 and $-0.89 \%$ respectively for nitrate and sulfate. These $\lambda$ 
458 values were lower than those along the flow path in the DNAPL source area $(0.0039$

459 and $0.0075 \mathrm{~m}^{-1}$, and -8.66 and $-7.88 \%$ respectively for nitrate and sulfate), where

460 nitrite, $\mathrm{Mn}^{2+}$, and $\mathrm{Fe}^{2+}$ tended to increase. All these elements agree with the mentioned

461 redox conditions in the source area.

462 Low Eh and DO values were observed along the centerline of the plume in the TZBA

463 (Figure $3 A, B)$. This agrees with the high geological and textural heterogeneity of the

464 TZBA throughout the site (Section 4.1), which leads to: i) low hydraulic conductivity and

465 flow velocity, ii) little DO supply by groundwater, and iii) the consumption of this DO to

466 oxidize the dissolved TOC and natural organic matter in the TZBA, giving rise to high

467 anoxic conditions here and in the central part of the plume. This shows that geological

468 and textural heterogeneity is the key control that accounts for the high anoxic

469 conditions in the environment.

470 In contrast, Eh and DO values increased towards the periphery and frontal part of the

471 plume, showing the input of DO by hydrodynamic dispersion, which agrees with the

472 higher values of nitrate, sulfate, and TOC, and with the lower values of nitrite, $\mathrm{Mn}^{2+}$,

473 and $\mathrm{Fe}^{2+}$ in these parts.

474 
(A)

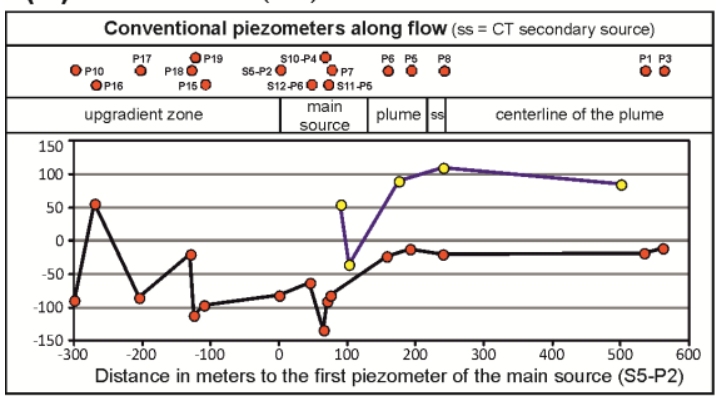

(C)

Nitrate $(\mathrm{mg} / \mathrm{L})$

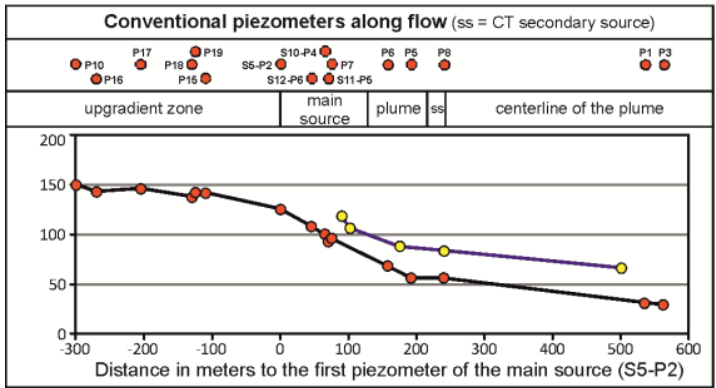

(E)

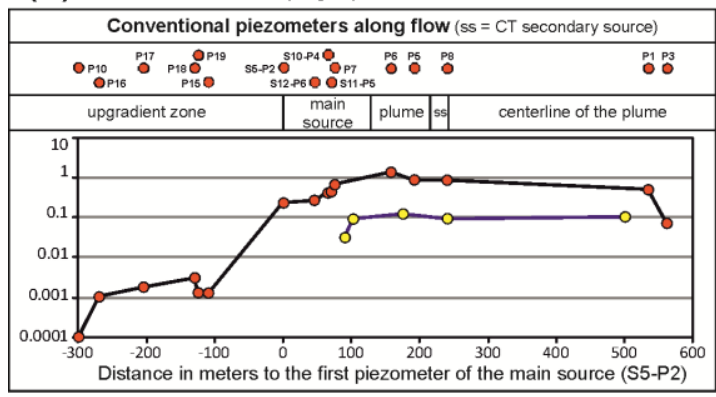

(G)

Sulfate $(\mathrm{mg} / \mathrm{L})$

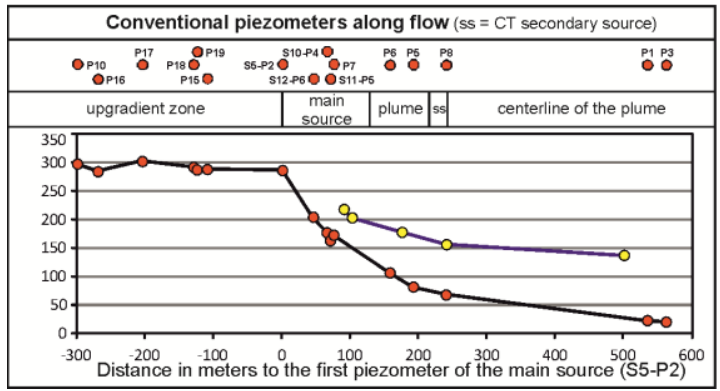

(B)

$\mathrm{DO}(\mathrm{mg} / \mathrm{L})$

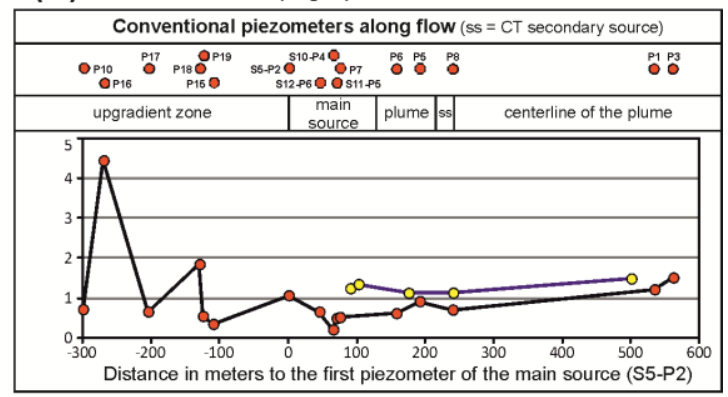

(D)

Nitrite $(\mathrm{mg} / \mathrm{L})$

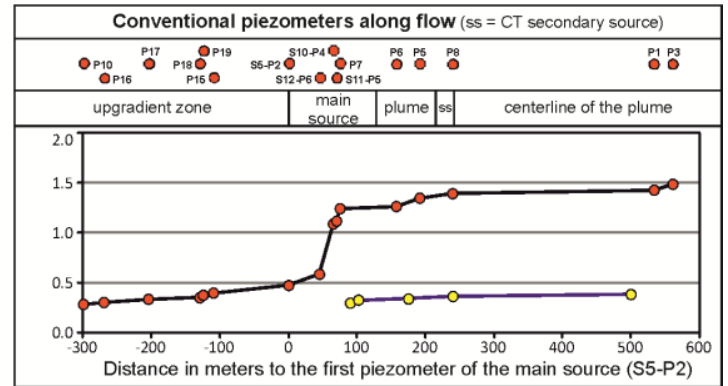

(F)

$\mathrm{Fe}^{2+}(\mathrm{mg} / \mathrm{L})$

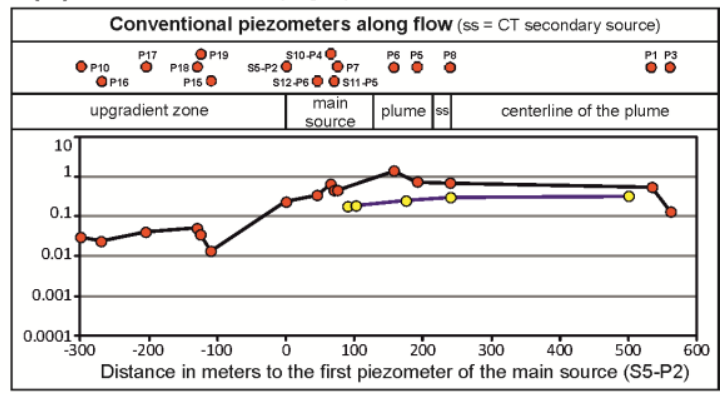

(H) TOC (mg/L)

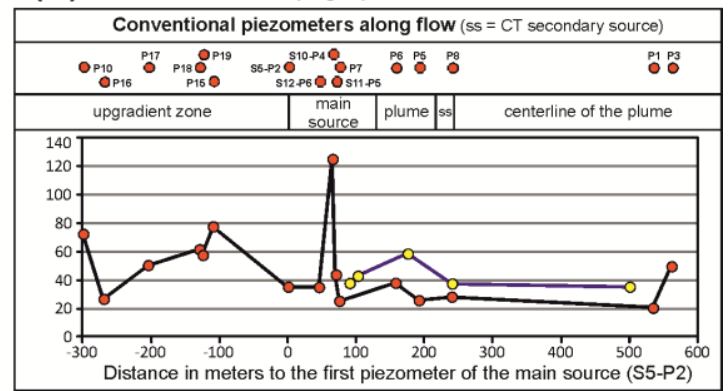

Figure 3. Summary of Eh values and concentrations of redox-sensitive parameters (DO, TOC, nitrate, nitrite, $\mathrm{Mn}^{2+}, \mathrm{Fe}^{2+}$, and sulfate) in the TZBA along the flow path (ss = CT secondary pool of DNAPL-source). Red line represents the centerline. Blue line is the average of peripheral zones.

481 Figure 4 ¡Error! No se encuentra el origen de la referencia. displays a summary of

482 the concentrations of chloromethanes and isotopic compositions of CT and CF in the

483 TZBA along the flow path. The highest concentration values of CT, CF, DCM, and CM 

and CF occurred downgradient of the main source at piezometer P8 (Figure 4A,C).

486 This finding reveals the existence of a small DNAPL pool, which is the secondary

487 source mentioned in Section 2. This source is isolated from the area of the main

488 DNAPL source and is located between piezometers P5 and P8.

489

(A)

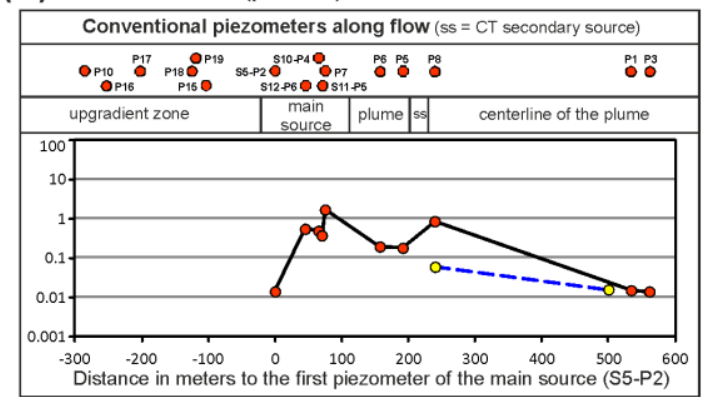

(B)

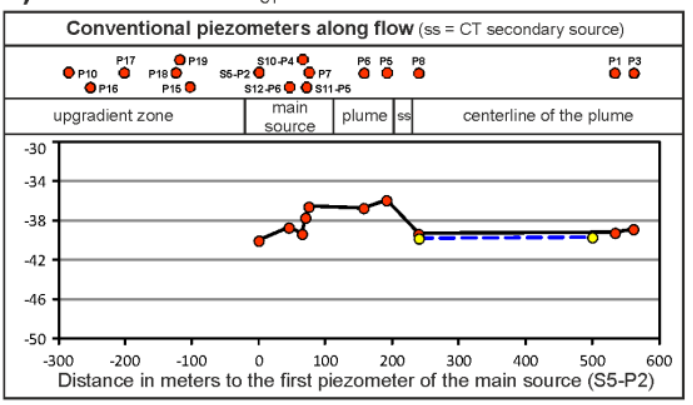

(E)

$\mathrm{DCM}(\mu \mathrm{mol} / \mathrm{L})$

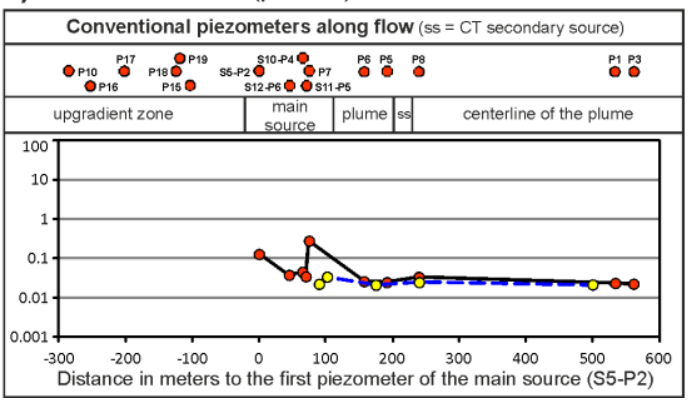

(C) CF $(\mu \mathrm{mol} / \mathrm{L})$

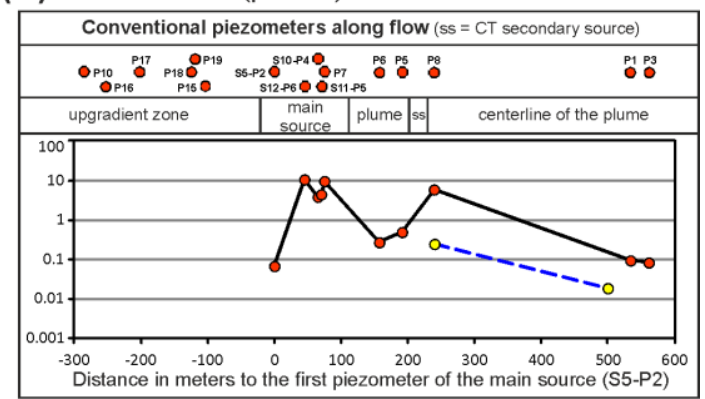

(D) $\overline{0} \%{ }^{13} \mathrm{C}_{\mathrm{CF}}$

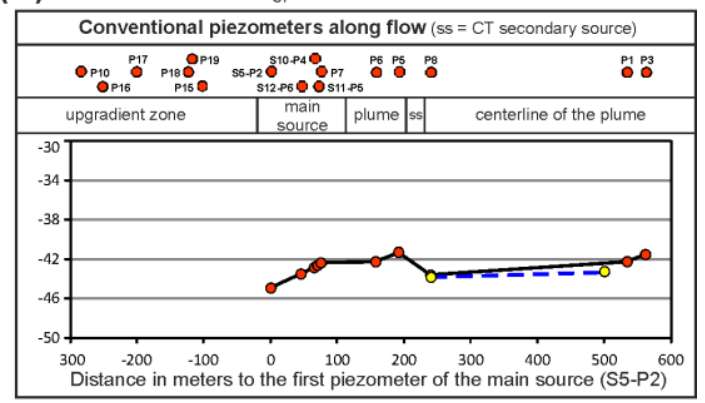

(F) CM ( $\mu \mathrm{mol} / \mathrm{L})$

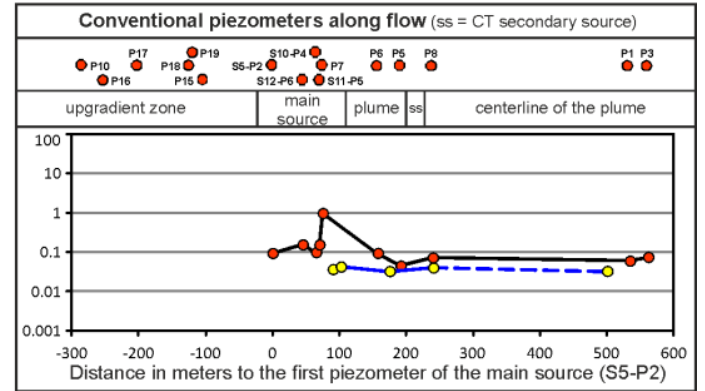

Figure 4. Summary of concentrations of chloromethanes and isotopic composition of CT and CF in the TZBA along the flow path (ss = CT secondary pool of DNAPLsource). Red line represents the centerline. Blue line is the average of peripheral zones. 


\subsubsection{Evidence of major degradation processes and dominant redox conditions}

497 In this section, the major redox-dependent transformation processes occurring in the

498 TZBA along the flow path are analyzed. The integration of these results allows

499 determination of the dominant redox conditions.

500 Figure $5 \mathrm{~A}$ shows that values of isotopic composition of nitrate fit to a denitrification line 501 originated in the field of the use of manure as fertilizer. The dominant redox conditions

502 in the zone upgradient of the source at the depth of the TZBA were denitrifying (Figure

$5036 \mathrm{6})$, as denitrification was the only redox dependent process identified in this area.

504 Nitrate and nitrite largely decreased and increased, respectively, in the TZBA along the 505 flow path between the main and secondary source (Figure 3C,D). In addition, the 506 heaviest $\delta^{15} \mathrm{~N}_{\text {nitrate }}$ and $\delta^{18} \mathrm{O}_{\text {nitrate }}$ values in the conventional piezometers (27.14 and $50721.82 \%$, respectively) were observed at the front of the plume. However, the highest

508 attenuation rate of nitrate and isotope enrichment factor for ${ }^{15} \mathrm{~N}$ along the flow path,

509 occurred in the main DNAPL source area (with $\lambda$ and $\varepsilon$ values of $0.0039 \mathrm{~m}^{-1}$ and -

$5108.66 \%$, respectively). All these results, as well as the increase in $\mathrm{Mn}^{2+}$ and $\mathrm{Fe}^{2+}$ (Figure

$5113 E, F)$, the decrease in sulfate (Figure 3G), and the low Eh and DO values (Figure

$5123 \mathrm{~A}, \mathrm{~B})$, are evidence that reduction processes of nitrate occurred in the TZBAalong the

513 flow path, especially along the main source area. The lower rate of attenuation and

514 isotope enrichment factor observed for nitrate downgradient of the source along the

515 centerline of the plume ( $\lambda$ and $\varepsilon$ values of $0.0020 \mathrm{~m}^{-1}$ and $-4.27 \%$ ) denoted that

516 denitrification still occurred (Figure 6A). 
(A)

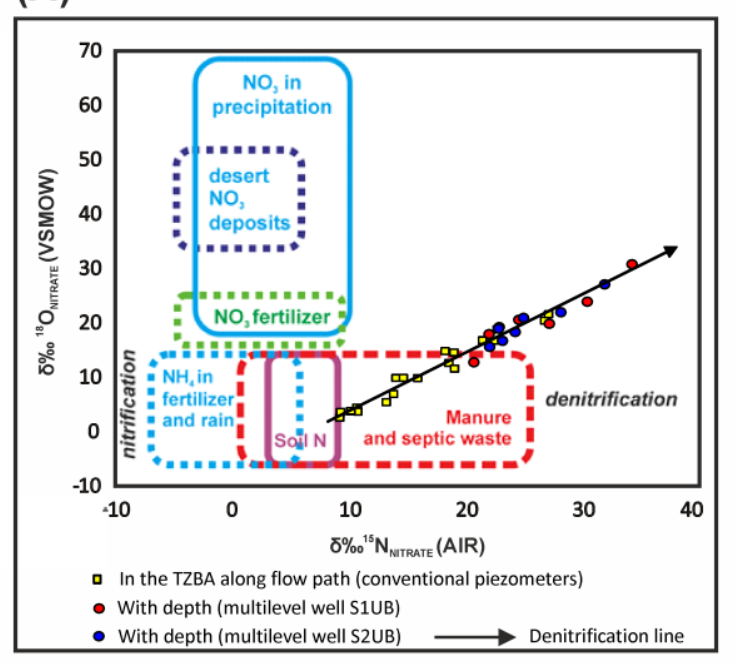

(B)

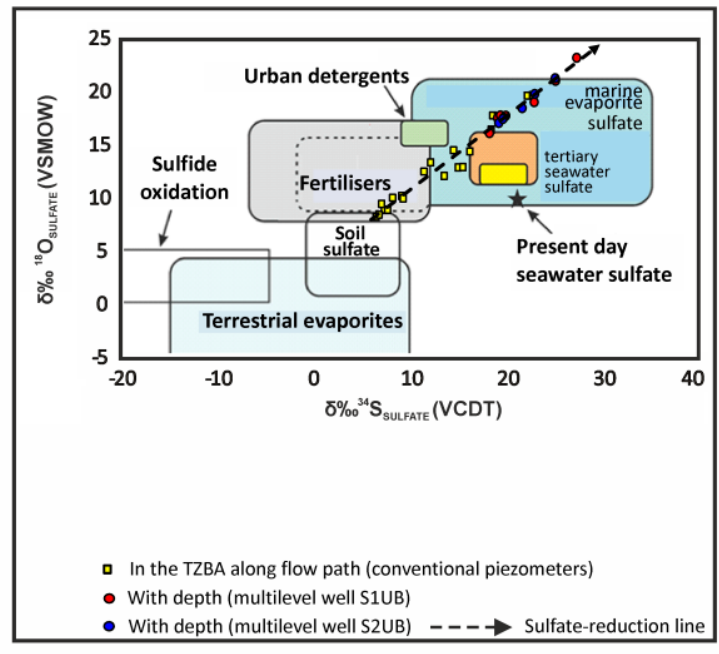

519 Figure 5. (A) Denitrification line in the TZBA along the flow path and with depth. (B)

520 Sulfate-reduction line in the TZBA along flow path and with depth.

522 While $\mathrm{Mn}^{2+}$ and $\mathrm{Fe}^{2+}$ were low upgradient of the DNAPL source area (Figure 3E,F),

523 with values that corresponded to background values, they increased in the source and

524 immediately downgradient of this area. These observations, the low Eh and DO values

525 (Figure 3B), and the reductive dechlorination and sulfate-reduction processes (see

526 below) provide evidence that reduction occurred for the oxidized minerals of

527 manganese and iron along the flow path in sediments of the TZBA (Figure 6A).

528 While CT and CF, and the other chloromethanes concentrations were below the LOQ

529 in the TZBA along the flow path upgradient of the main source, a large increase was

530 progressively recorded in the source area, where the highest values of CT and CF

531 were recorded (Figure 4A,C). This increase was accompanied by the isotopic

532 fractionation of these compounds (Figure 4B,D) as well as the formation of DCM and

533 CM (Figure 4E,F), demonstrating that degradation of CT and CF occurred. A similar

534 pattern of isotopic fractionation was observed downgradient of the main source,

535 although the highest attenuation rates and isotope $\varepsilon$ values of CT and CF in the TZBA

536 along the flow path also occurred at the source, with $\lambda$ values of 0.0684 and $0.0671 \mathrm{~m}^{-}$

$537{ }^{1}$, respectively; and $\varepsilon$ values of -3.58 and $-2.67 \%$, respectively. Although $\delta^{13} \mathrm{C}_{\mathrm{CT}}$ and 
$538 \delta^{13} \mathrm{C}_{\mathrm{CF}}$ increased in the source area (Figure 4B,D), the aforementioned $\varepsilon$ values, are 539 underestimated since light CT is continuously dissolved from the CT contained in the

540 DNAPL source and incorporated into the groundwater flow. As regards CF, the

541 increase in fractionation of this compound, caused by its transformation into DCM,

542 must be added to similar effects as those described for CT (i.e., light CF incorporating

543 into groundwater from the CF contained in the DNAPL source) and by the CF

544 proceeding from CT transformation. Given that the described degradation process of

545 CT and CF occurred in parallel with the reduction of nitrate, natural oxidized

546 manganese and iron minerals, and sulfate (see below), and consequently under highly

547 anoxic redox conditions (see Section 4.2.1), it is plausible to affirm that it corresponds

548 to reductive dechlorination of chloromethanes (Figure 6A). This process overlapped

549 with the aforementioned biogeochemical process of denitrification, and despite the fact

550 that the reduction potential of nitrate is greater than that of CT and CF, degradation of

551 these compounds was not inhibited because of the highly anoxic conditions. The

552 increase in CT that was observed between piezometers P5 and P8 (Figure 4;Error! No

553 se encuentra el origen de la referencia.A, i.e., in the secondary source, see Section

554 4.2.1) corresponded to an isotopic composition of this compound with a $\delta^{13} \mathrm{C}_{\mathrm{CT}}$ value of

$555-39.30 \%$ in P8 (Figure 4¡Error! No se encuentra el origen de la referencia.B), which

556 was similar to that of the main source in S5-P2 (-39.98\%o). By contrast, the isotopic

557 composition of $\mathrm{CF}$ in $\mathrm{P} 8\left(\delta^{13} \mathrm{C}_{\mathrm{CF}}\right.$ of $-43.60 \%$, ¡Error! No se encuentra el origen de la

558 referencia.D) was heavier than that of the main source in S5-P2 $\left(\delta^{13} \mathrm{C}_{\mathrm{CF}}\right.$ of $\left.-44.92 \%\right)$.

559 This finding suggests that the secondary pool is composed only of CT-DNAPL and that

560 the increase in CF is caused by the degradation of CT. This pattern supports the fact

561 that the DNAPL leaks originated from two different tanks, one for CT and the other for

562 CF (see Section 2).

563 In the main DNAPL source, the ratio of the average molar concentration of CT to that of

564 CF was 1 mole of CT per 9.25 moles of CF. By contrast, in the TZBA along the axial 
zone of the plume (and in its peripheral area, where conditions were not as reducing),

566 the ratio was 1 mole of CT per 2.32 moles of CF. In addition, isotopic fractionation of

567 CT was not recorded (Figure 4¡Error! No se encuentra el origen de la referencia.B), and low concentrations of DCM and CM were measured in the plume (Figure 4 ¡Error!

No se encuentra el origen de la referencia.E,F), thus indicating a larger

570 transformation of CT to CF (and successively, DCM and CM) in the source than in the

571 plume (Figure 6A). By contrast, a decrease in the CF concentration (Figure 4;Error!

572 No se encuentra el origen de la referencia.C) accompanied by the isotopic

573 fractionation of this compound (Figure 4¡Error! No se encuentra el origen de la

574 referencia.D) occurred along the centerline of the plume, which gave rise to an

575 attenuation rate and an isotope enrichment factor between conventional piezometer P7

576 (at the main source) and P3 (at the front of the plume) with $\lambda$ and $\varepsilon$ values of $0.0098 \mathrm{~m}^{-1}$

577 and $-0.89 \%$, respectively.

578 Figure $5 \mathrm{~B}$ shows that the $\delta^{34} \mathrm{~S}_{\text {sulfate }}$ and $\delta^{18} \mathrm{O}_{\text {sulfate }}$ values fit a sulfate-reduction line

579 originating in the sulfate-based fertilizers field). Sulfate largely decreased in the TZBA

580 along the flow path between the main and secondary sources (Figure 3G). Moreover,

581 the heaviest $\delta^{34} S_{\text {sulfate }}$ and $\delta^{18} \mathrm{O}_{\text {sulfate }}$ values (22.75 and $19.80 \%$, respectively) were

582 observed at the front of the plume. Nevertheless, as in the case of nitrate, CT, and CF,

583 the highest rate of attenuation and enrichment factor for sulfate in the DNAPL source

584 area were the highest (with $\lambda$ and $\varepsilon$ values of $0.0075 \mathrm{~m}^{-1}$ and $-7.88 \%$, respectively). All

585 these observations and the low Eh and DO values (Figure $3 A, B$ ) demonstrate that

586 sulfate-reduction occurs along the flow path in the main source (Figure 6A) and

587 downgradient in the plume, where the environment was highly anoxic (Figure 6B). This

588 indicates that dominant redox conditions are sulfate-reducing in the source and the

589 plume at the depth of the TZBA (Figure 6B), according to the thermodynamic model

590 described by Christensen et al. (2000)(see Section 3.1). 
591 The sulfate-reduction process requires more extreme reducing conditions than do the

592 rest of the other processes occurring in the main source and the plume (Figure 6A).

593 This accounts for the smaller concentrations of $\mathrm{Fe}^{2+}$ and $\mathrm{Mn}^{2+}$ and their smaller

594 increase than those observed downgradient of the source (Figure 3E,F) since the

595 precipitation of these metals in a reduced state occurs under these reducing conditions

596 as carbonates and sulfides (rhodochrosite $\mathrm{MnCO}_{3}$ and siderite $\mathrm{FeCO}_{3}$; manganous

597 sulfide MnS, ferrous sulfide FeS and pyrite $\mathrm{FeS}_{2}$ ). A core sampling survey carried out

598 by Puigserver et al. (2013) in boreholes B-S1UB and B-S2UB registered high values of

$599 \mathrm{Mn}$ and $\mathrm{Fe}$ in sediments of the TZBA at depths similar to those of the source of CT and

$600 \mathrm{CF}$, which could be evidence of precipitation of the Mn and Fe minerals.

601 At the depth of the TZBA, the rate of attenuation observed for sulfate downgradient of

602 the source was lower than at the source $\left(\lambda\right.$ value of $\left.0.0030 \mathrm{~m}^{-1}\right)$, demonstrating that the

603 sulfate-reduction process still occurred in the plume (Figure 6A), and even in the

604 peripheral zone (Figure 3G), regardless of the environment was less anoxic because

605 Eh and DO progressively increased (Figure 3A,B).

606 In summary, the dominant sulfate-reducing redox conditions control the processes

607 occurring along the flow path at the depth of the TZBA in the study site, including the

608 reductive dechlorination of CT and CF (Figure 6B). This process takes place at a very

609 high rate in the main DNAPL source in a highly anoxic environment (Figure 6B, with

610 DO ranging between 0.20 and $0.65 \mathrm{mg} / \mathrm{L})$. The high geological and textural

611 heterogeneity in the TZBA (see Section 4.1) that led to low DO supply and its

612 subsequent consumption in the oxidization of the dissolved TOC and natural organic

613 matter in fine sediments, gave rise to the anoxic conditions (see Section 4.2.1) that

614 favored the reductive dechlorination of chloromethanes.

615 


\begin{tabular}{|c|c|c|c|c|}
\hline \multicolumn{5}{|c|}{ Dominant redox conditions along flow in the TZBA based on the major transformation processes identified } \\
\hline & $\begin{array}{llll}\mathrm{P}_{0}^{10} & \circ & \circ & \infty^{\mathrm{P} 15}\end{array}$ & 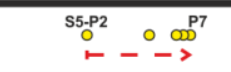 & $\stackrel{\text { P6 }}{\text { P5 }}$ & $\circ \stackrel{P}{0}^{p_{3}}$ \\
\hline \multirow{5}{*}{$\begin{array}{r}\text { Major } \\
\text { identified } \\
\text { proceses }\end{array}$} & $\begin{array}{l}\text { Denitrification } \\
\text { (very low rate) }\end{array}$ & $\begin{array}{l}\text { Denitrification } \\
\text { (very high rate) }\end{array}$ & $\begin{array}{c}\text { Denitrification } \\
\text { (low rate) }\end{array}$ & $\begin{array}{l}\text { Denitrification } \\
\text { (very low rate) }\end{array}$ \\
\hline & & Mn-reduction & \begin{tabular}{|c|} 
Mn-reduction \\
(high rate)
\end{tabular} & \\
\hline & & Fe-reduction & $\begin{array}{c}\text { Fe-reduction } \\
\text { (high rate) }\end{array}$ & \\
\hline & & $\begin{array}{l}\text { R. dechlorination } \\
\text { (very high rate) }\end{array}$ & $\begin{array}{c}\text { Red. dechl. } \\
\text { (high rate) }\end{array}$ & $\begin{array}{l}\text { R. dechlorination } \\
\text { (low rate) }\end{array}$ \\
\hline & & $\begin{array}{c}\text { Sulfate-reduction } \\
\text { (very high rate) }\end{array}$ & $\begin{array}{l}\text { Sulf.-red. } \\
\text { (low rate) }\end{array}$ & $\begin{array}{c}\text { Sulfate-reduction } \\
\text { (low rate) }\end{array}$ \\
\hline $\begin{array}{r}\text { Dominant } \\
\text { Redox } \\
\text { conditions }\end{array}$ & (denitrifying) & $\begin{array}{l}\text { (sulfate-reducing) } \\
\text { highly anoxic } \\
\text { environment }\end{array}$ & (sulf.-red.) & $\begin{array}{l}\text { (sulfate-reducing) } \\
\text { highly anoxic } \\
\text { environment }\end{array}$ \\
\hline
\end{tabular}

617 Figure 6. Major identified processes and dominant redox conditions in the TZBA along

618 the flow path. Analyses based on results shown in Figure 3, Figure 4 and Figure 5.

619 Possible precipitation of carbonate and sulfide minerals of $\mathrm{Mn}$ and Fe could occur in

620 the main source.

\subsection{Degradation processes and dominant redox conditions with depth}

623 The following is a detailed perspective of two biogeochemical profiles of groundwater

624 depth in the UPA and TZBA, obtained in the two multilevel wells (S1UB and S2UB)

625 located in the axis of the chloromethanes plume $220 \mathrm{~m}$ downgradient of the main

626 DNAPL source (Figure 1).

\subsubsection{Eh values and redox-sensitive parameters and chloromethanes}

629 A summary of the variation of Eh values and concentrations of redox-sensitive

630 parameters (DO, TOC, nitrate, nitrite, $\mathrm{Mn}^{2+}, \mathrm{Fe}^{2+}$, and sulfate) with depth is shown in

631 Figure 7. Eh and DO decreased at the depths of the UPA (ports 1 to 4, Figure 7A,B),

632 which is consistent with reducing conditions and with the fact that nitrate and sulfate

633 concentrations decreased and nitrite, $\mathrm{Mn}^{2+}$, and $\mathrm{Fe}^{2+}$ increased (Figure 7). However,

634 the most highly anoxic conditions occurred at depths of the TZBA (ports 5 to 7), with an

635 average Eh value of $-24 \mathrm{mV}$, which coincided with a high average TOC value of 32.4

$636 \mathrm{mg} / \mathrm{L}$, whose oxidation favored DO consumption. This TOC content was close to that of 
637 the average values of conventional piezometers P5 and P8 at the depth of the TZBA

638 (27.4 mg/L), which are nearby S1UB and S2UB. As in the source, TOC concentrations

639 in the plume agree with the high organic carbon background at the site and with the

640 abundant natural particulate and dissolved organic matter in the numerous interbedded

641 layers of fine material of the TZBA, which again denotes that the great geological and

642 textural heterogeneity of this hydrostratigraphic unit is the key control that gives rise to

643 highly anoxic conditions (similar to those at the main source, see Section 4.2.1). Under

644 these highly anoxic conditions, concentrations of nitrate and sulfate decreased from

645 port 5 to 7 (Figure 7D,E; with average values of $28.8 \mathrm{mg} / \mathrm{L}$ and $38.3 \mathrm{mg} / \mathrm{L}$,

646 respectively), whereas nitrite, $\mathrm{Mn}^{2+}$ and $\mathrm{Fe}^{2+}$ tended to increase (Figure 7F,G,H; with

647 average values of $1.9 \mathrm{mg} / \mathrm{L}, 1.3 \mathrm{mg} / \mathrm{L}$, and $2.4 \mathrm{mg} / \mathrm{L}$, respectively). 
(A)

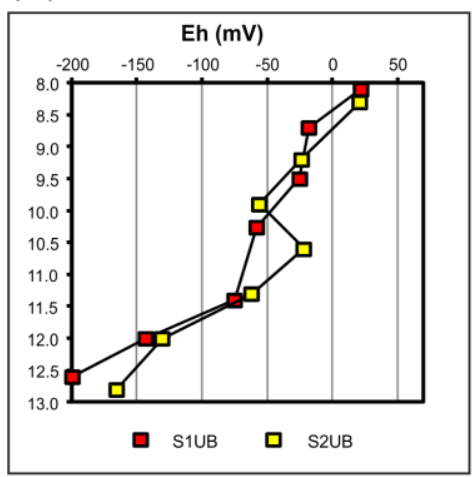

(D)

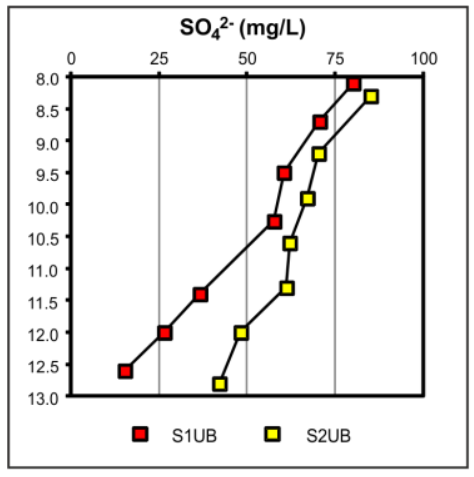

(G)

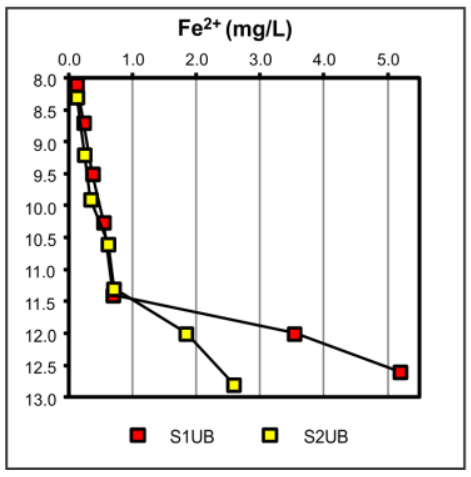

(B)

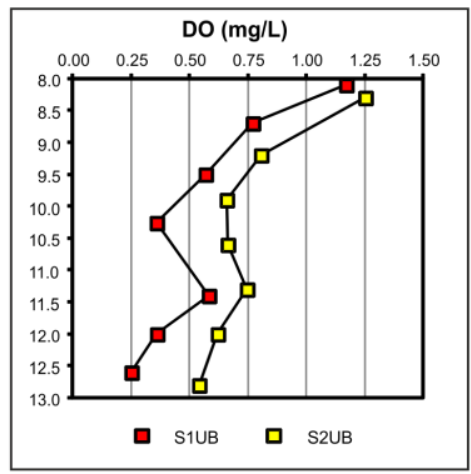

$(\mathrm{E})$

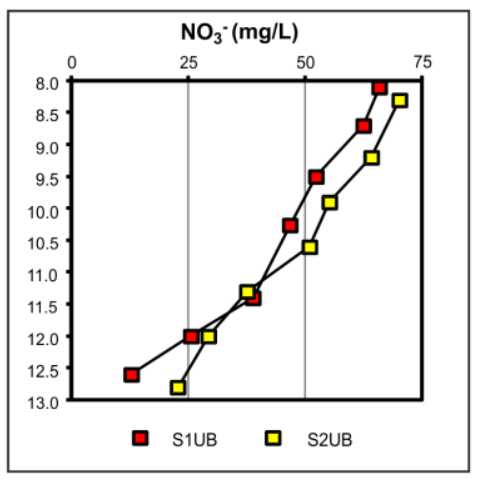

$(\mathrm{H})$

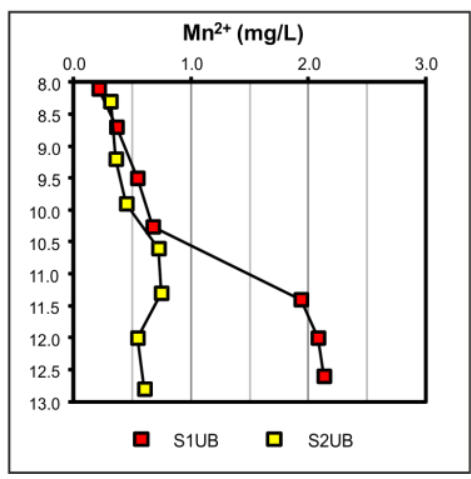

(C)

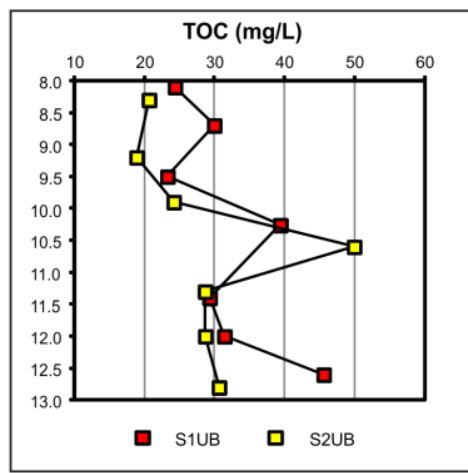

$(\mathrm{F})$
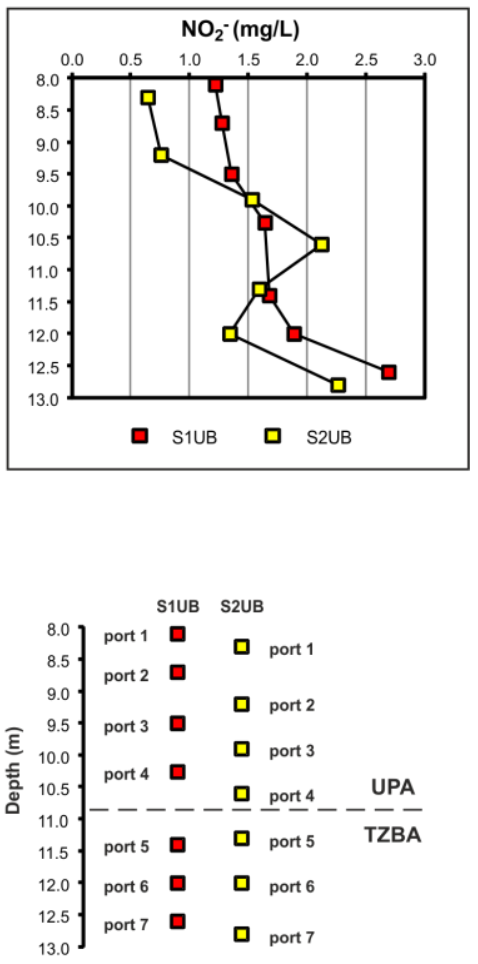

Figure 7. Variation of Eh values and concentrations of redox-sensitive parameters 650 (DO, TOC, nitrate, nitrite, $\mathrm{Mn}^{2+}, \mathrm{Fe}^{2+}$, and sulfate) with depth. UPA (Upper Part of the 651 Aquifer). TZBA (Transition Zone to the BottomAquitard).

653 As for chloromethanes, Figure 8 displays a summary of their concentrations and the

654 isotopic composition of CT and CF with depth. The highest values of CT were found at

655 the top of the TZBA (port 5), whereas the highest values of CF, DCM, and CM were

656 recorded at the bottom of this unit (ports 6 and 7). 
(A)

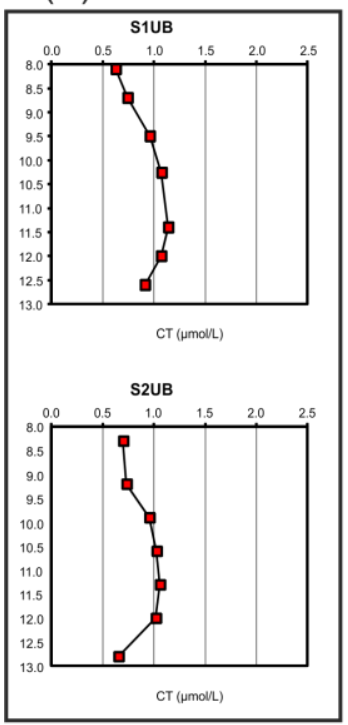

(B)

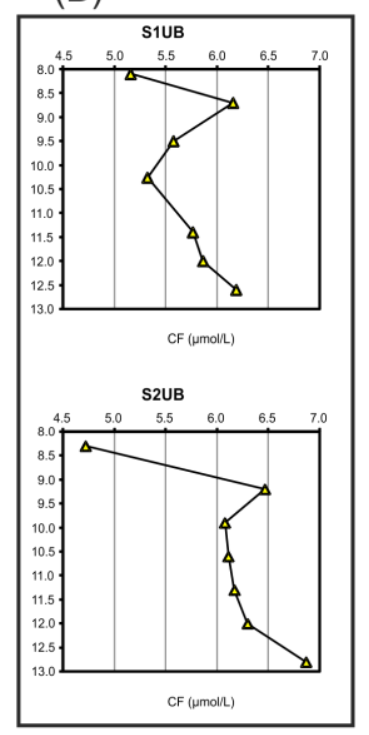

(C)

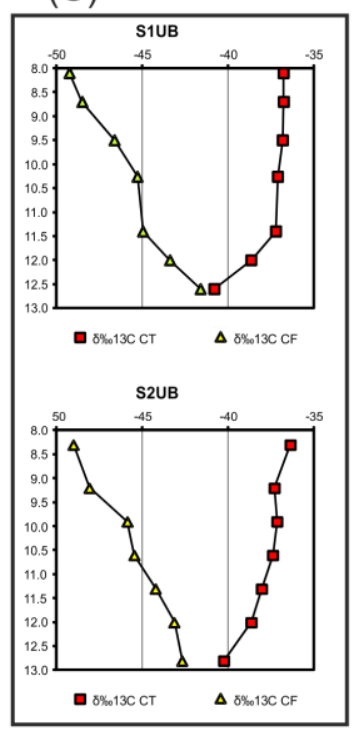

(D)

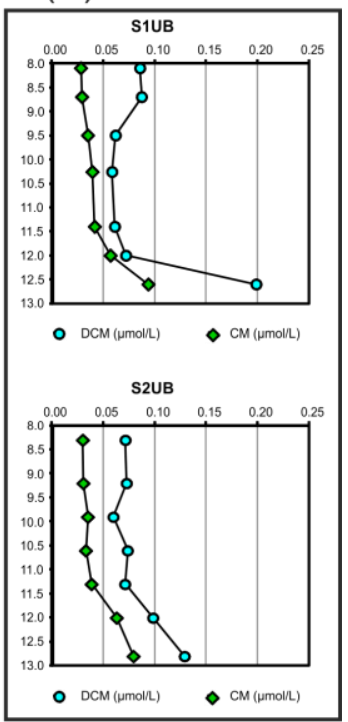

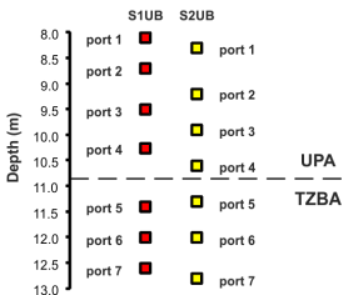

659 Figure 8. Variation of concentrations of chloromethanes and isotopic composition of 660 CT and CF with depth. UPA (Upper Part of the Aquifer). TZBA (Transition Zone to the 661 Bottom Aquitard).

662

\subsubsection{Evidence of major degradation processes and dominant redox conditions}

664 Figure 9A shows the major redox-dependent transformation processes that occurred

665 and the redox conditions that were dominant with depth in the UPA and TZBA (Figure $6669 \mathrm{9})$.

667 As with along the flow path in the TZBA, denitrification of nitrate was recorded with depth (Figure 5A). The vertical concentration profiles of nitrate and nitrite (Figure 7E,F) showed a higher decrease of nitrate and an increase of nitrite in the TZBA (ports 5 to 7 )

670 compared to those in the UPA (ports 1 to 4), where denitrification from the zone

671 upgradient of the DNAPL source to ports of multilevel wells in the plume occurred at a

672 lower attenuation rate and isotope enrichment factor than in the TZBA (with $\lambda$ of nitrate 673 and $\varepsilon$ for ${ }^{15} \mathrm{~N}$ values of 0.0037 and $0.0069 \mathrm{~m}^{-1}$, and -13.38 and $-19.91 \%$, respectively in 
674 the UPA and TZBA). All these results, in addition to the increase in Fe ${ }^{2+}$ (Figure 7G),

675 the decrease in sulfate (Figure 7D), and the low Eh and DO values in the depth profile

676 of the TZBA (Figure 7A,B), are evidence that, although denitrification, does occur in the

677 UPA, this process is more relevant in the TZBA (Figure 9B).

678 The $\mathrm{Fe}^{2+}$ and $\mathrm{Mn}^{2+}$ concentrations varied little in the UPA, but increased in the TZBA, especially $\mathrm{Fe}^{2+}$, indicating the occurrence of Fe-reduction processes (Figure 9A).

680 In multilevel wells S1UB and S2UB, gradual increases in CT from port 1 to 4 in the 681 UPA and decreases from 5 to 7 in the TZBA (Figure 8A) were recorded. As reported by 682 Puigserver et al. (2013) at this site, these maximums in groundwater coincided with two 683 CT concentration peaks in the PWFS of boreholes B-S1UB and B-S2UB, which were 684 caused by the secondary small DNAPL pool of CT (see Section 4.2.1). Although CT in 685 groundwater decreased in the TZBA, $\delta^{13} \mathrm{C}_{\mathrm{C}}$ values also decreased with depth (Figure $6868 \mathrm{C}$ ), demonstrating that the input of dissolved CT from the secondary pool (which is 687 isotopically light) masks the isotopic fractionation of this compound in groundwater in 688 ports 5 to 7 of the TZBA. The CF concentrations and $\delta^{13} \mathrm{C}_{\mathrm{CF}}$ values increased with 689 depth in ports 1 to 4 of the UPA (Figure 8B,C). This isotopic fractionation of CF in the 690 UPA was accompanied by a slight increase in the DCM concentration, along with the 691 formation of CM (Figure 8D). As for the TZBA, an increase in CF, DCM, and CM was detected, along with isotopic fractionation of CF (Figure 8B,C,D). Furthermore, the

693 variation of concentrations of chloromethanes in groundwater at the TZBA occurred in 694 parallel to a similar variation of these compounds in PWFS (Puigserver et al., 2013), 695 particularly in sediments found at the depth of port 7 of multilevel wells. All these 696 elements and the increase with depth of CF, DCM, and CM in ports 5 to 7 of the TZBA, 697 as well as the sulfate-reducing conditions prevailing in the TZBA along the flow path 698 (see Section 4.2.2) and with depth (see below), are evidence that the reductive 699 dechlorination of CT and CF (and of DCM) is a more substantial process in the TZBA 700 than in the UPA, with higher attenuation rates and isotope $\varepsilon$ values for CT and CF from 
701 the source zone to ports 5 to 7 of multilevel wells in the TZBA ( $\lambda$ and $\varepsilon$ of $0.0044 \mathrm{~m}^{-1}$ 702 and $-3.42 \%$, respectively for $\mathrm{CT}$, and of $0.0045 \mathrm{~m}^{-1}$ and $-2.72 \%$, respectively for CF) 703 than in the UPA in ports 1 to 4 ( $\lambda$ and $\varepsilon$ of $0.0029 \mathrm{~m}^{-1}$ and $-0.81 \%$, respectively for CT, 704 and of $0.0006 \mathrm{~m}^{-1}$ and $-1.15 \%$ for $\mathrm{CF}$, respectively).

705 As along the flow path, sulfate evolution with depth showed that the sulfate-reduction 706 process also occurred (Figure 5B). The sulfate variation from the zone upgradient of

707 the DNAPL source to the plume at depths in the sampling ports in the multilevel wells, 708 registered a greater decrease at ports 5 to 7 in the TZBA than at ports 1 to 4 in the 709 UPA (Figure 7D). These differences correspond to different attenuation rates and 710 enrichment factors between the two hydrostratigraphic units, with higher attenuation 711 rate and isotope enrichment factor in the TZBA than in the UPA ( $\lambda$ of sulfate and $\varepsilon$ for ${ }^{34} \mathrm{~S}$ values of 0.0085 and of $0.0060 \mathrm{~m}^{-1}$, and -17.10 and $-12.63 \%$, respectively).

713 As in the main DNAPL source (see Section 4.2.2), groundwater of ports 5 to 7 in the

714 TZBA showed dominant sulfate-reducing redox conditions in an environment that was 715 more anoxic than in the UPA (Figure 9B). All these results, along with the increase in $716 \mathrm{Fe}^{2+}$ (Figure $\left.7 \mathrm{G}\right)$, the decrease in sulfate, and the low Eh and DO values (Figure 7A,B), 717 reveal that although sulfate-reduction also occurs in the UPA, this process is 718 particularly noteworthy in the TZBA.

719 This highly anoxic environment in the TZBA explains the very low increases in $720 \mathrm{Mn}^{2+}$ concentrations in the TZBA compared to the UPA (Figure $7 \mathrm{H}$ ), since manganese

721 in a reduced state could precipitate as carbonate (rhodochrosite $\mathrm{MnCO}_{3}$ ) and as 722 manganous sulfide (MnS). Evidence of precipitation of Mn minerals could be the high 723 aforementioned Mn values in sediments along the flow path at the depth of the TZBA 724 (see Section 4.2.2).

725 In summary, depth profiles obtained with multilevel wells S1UB and S2UB in the TZBA 726 confirm that reductive dechlorination of CT and CF is controlled by the dominant 727 sulfate-reducing redox conditions (as was observed along the flow path in the zone of 
728 the plume close to conventional piezometer P8). Moreover, these profiles allow

729 affirming that these redox conditions occur in a highly anoxic environment (Figure 9B),

730 since DO contents from ports 5 to 7 (Figure 7B) varied between 0.25 and $0.75 \mathrm{mg} / \mathrm{L}$.

731 As is the case along the flow path, the great geological and textural heterogeneity in

732 the TZBA is the key control that accounts for the very low DO content (see Section

733 4.2.1), and consequently, also for the sulfate-reducing conditions and the highly anoxic

734 environment.

735 These conditions are close to those along the flow path in the main source area (Figure

736 6B). Accordingly, attenuation rates and isotope enrichment values of CT with depth in

737 the TZBA ( $\lambda$ and $\varepsilon$ calculated between the maximum concentration in the source

738 (piezometer P7) and ports of multilevel wells in the TZBA, see Section 3.1) were close

739 to those in the main source along the flow path $\left(\lambda\right.$ and $\varepsilon$ with depth of $0.0044 \mathrm{~m}^{-1}$ and -

$7403.42 \%$, respectively; and $\lambda$ and $\varepsilon$ in the main source of $0.0684 \mathrm{~m}^{-1}$ and $-3.58 \%$,

741 respectively, see Section 4.2.2). Similarly, for the case of CF, attenuation rates and

742 isotope enrichment were close to those of the main source $(\lambda$ and $\varepsilon$ with depth of

$7430.0045 \mathrm{~m}^{-1}$ and $-2.72 \%$, respectively; and $\lambda$ and $\varepsilon$ of $0.0671 \mathrm{~m}^{-1}$ and $-2.67 \%$,

744 respectively, see Section 4.2.2).

745 By contrast, attenuation rates (Figure 9A) and isotope enrichment values of CT and CF 746 were higher in the TZBA than in the UPA. Thus, $\lambda$ and $\varepsilon$ values of $0.0044 \mathrm{~m}^{-1}$ and -

$7473.42 \%$, respectively for CT; and $0.0045 \mathrm{~m}^{-1}$ and $-2.72 \%$, respectively for CF were

748 obtained in the TZBA; whereas, $\lambda$ and $\varepsilon$ values of $0.0029 \mathrm{~m}^{-1}$ and $-0.81 \%$, respectively

749 for CT; an

$750 \mathrm{~d} 0.00406 \mathrm{~m}^{-1}$ and $-1.15 \%$, respectively for CF were obtained in the UPA. 
B)

A)

Dominant
Redox conditions

Dominant redox conditions along flow based on the major transformation processes identified

753

754

755

756

757

758

759

760

761

762

763

764

765

766

767

768

769

770

771

Figure 9. Major identified processes and dominant redox conditions with depth. Analysis based on results shown in Figure 7and Figure 8. Possible precipitation of carbonate and sulfide minerals of Mn could occur in the TZBA.

\subsection{Microbe diversity and abundance in groundwater and PWFS with depth}

Analyses of the DGGE profiles of the set of samples of groundwater and PWFS uncovered a total of 29 bands (results on diversity and abundance in each DGGE

profile are referred to this quantity, Table 1). Of these, the profiles of groundwater in the UPA showed in general greater average diversity and abundance (i.e., greater number of bands and greater brightness of bands, respectively of microbial communities in this hydrostratigraphic unit than in the TZBA, Table 1). This finding supports that the top of the UPA, which is found immediately below the water table oscillation zone, constitutes an ecotone in the subsurface (i.e., a natural zone where exchanges between two ecological systems of adjacent microbial communities occur), as demonstrated by Goldscheider et al. (2006) in unconfined aquifers. Furthermore, a large microbial diversity (value of 13), detected at port 3 of S1UB (central part of the UPA at $9.50 \mathrm{~m}$ deep), coincided with high microbial diversity (value of 6) in the PWFS sampled at a similar depth in borehole B-S1UB (sample M1 at $9.61 \mathrm{~m}$ depth), where a geological contact between coarse and fine materials occurred. 
772 In the TZBA, the contact surfaces between the different texture materials also

773 constitute ecotones (as described by Goldscheider et al., 2006). However, as

774 mentioned above, a decrease in the average diversity and abundance was observed

775 with depth in groundwater compared to what was observed in the UPA (Table 1). This decrease was more drastic in the TZBA of S1UB than in S2UB, which is consistent with the lower grain size in S1UB (and accounts for its lower hydraulic conductivity, see

778 Section 4.1 and Figure 2B), as reported by Puigserver et al. (2013) for this site. The 779 high amount of fine sediments and the variable matrix content of coarser sediments in the TZBA (see Section 4.1) makes it convenient to compare the grain size and average diameter of pore throats with the size of microorganism cells in the subsoil. Thus, the classical sedimentological literature provides grain sizes smaller than $2 \mu \mathrm{m}$ for clays, and sizes ranging from 2 to $50 \mu \mathrm{m}$ for silts. Moreover, Shuangfang et al. (2018), in a study on pore throat diameters in fine sediments, reported diameter values ranging from 0.09 to $0.86 \mu \mathrm{m}$ for clayey and silty sediments, which are coherent with grain sizes of fine sediments. The maximum of this range of pore throat diameters, rounded to $0.9 \mu \mathrm{m}$, could be considered as the pore throat threshold that inhibits the migration of bacteria through groundwater. The results recorded by different authors for the size of most subsoil cell bacteria range between 0.2 and $5 \mu \mathrm{m}$ (Alexander, 1978; Amodu,

790 Ojumu and Ntwampel, 2013; Portillo et al., 2013; Joergensen and Wichern, 2018). The

791 pore throat threshold diameter of $0.9 \mu \mathrm{m}$ is greater than the value of $0.2 \mu \mathrm{m}$,

792 corresponding to the size of the smallest cells. This is why a considerable portion of 793 microorganisms (those greater than $0.9 \mu \mathrm{m}$ ) are physically unable to penetrate into the 794 fine sediments and into the fine matrix of coarse sediments and in the TZBA, which 795 accounts for the decline in diversity and abundance observed in multilevel wells in this 796 unit (Table 1).

797 This is an important outcome for any contamination scenario in the subsoil, because 798 biostimulation or bioaugmentation actions cannot be conducted if a significant part of 
799 the microorganisms living in the aquifer cannot penetrate the fine sediments of the

800 transition zone (or the fine sediments at other depths in the aquifer). The relevance of

801 this lies in the need to verify whether the microorganisms proposed to biostimulate, or

802 those that are intended to be introduced in bioaugmentation actions, can migrate

803 through the finest subsoil materials before implementing such remediation strategies.

804 In the case of the site studied, Figure 10A,B,C,D shows that the two microorganisms

805 involved in the degradation of CT and CF (see Section 4.5) are small enough to flow

806 with groundwater and, in the case of $A$. suillum, to penetrate into the PWFS in the

807 TZBA (Figure 10C).

808 In summary, from the point of view of the structure of microbial communities, the

809 geological and textural heterogeneity is one of the elements that determine the

810 diversity and abundance of microorganisms in the subsurface. In addition, these

811 heterogeneities, especially textural heterogeneity, are factors that condition the

812 penetration of dechlorinating microorganisms into fine and less-conductive materials of

813 the TZBA, where they are responsible for the natural attenuation of CT and CF (see

814 Section 4.5.2), which penetrated via molecular diffusion into the less fine and less-

815 conductive materials.

816 


\begin{tabular}{|c|c|c|c|c|c|}
\hline & & & \multirow{2}{*}{\multicolumn{2}{|c|}{$\begin{array}{c}\text { Diversity } \\
\text { (average values) }\end{array}$}} & \multirow{3}{*}{$\begin{array}{c}\begin{array}{c}\text { Abundance } \\
\text { (average values) }\end{array} \\
\mathbf{C} \\
\end{array}$} \\
\hline & & & & & \\
\hline & & & A & B & \\
\hline & & $\begin{array}{l}\text { Hydrostratigraphic } \\
\text { unit }\end{array}$ & $\begin{array}{l}\text { Number } \\
\text { of bands } \\
\text { in } \\
\text { profiles }\end{array}$ & $\begin{array}{c}\text { Percentage } \\
\text { values } \\
(\%) \\
\end{array}$ & $\begin{array}{c}\text { Brightness intensity } \\
\text { of bands in profiles } \\
\text { (on a } 0-100 \text { scale) }\end{array}$ \\
\hline \multirow{4}{*}{$\begin{array}{l}\text { Multilevel } \\
\text { wells } \\
\text { (GW) }\end{array}$} & \multirow{2}{*}{ S1UB } & UPA & 7.5 & 25.86 & 42.78 \\
\hline & & TZBA & 3.7 & 12.64 & 34.99 \\
\hline & \multirow{2}{*}{ S2UB } & UPA & 5.3 & 18.10 & 43.08 \\
\hline & & TZBA & 5.0 & 17.24 & 36.73 \\
\hline \multirow{4}{*}{$\begin{array}{l}\text { Boreholes } \\
\text { (PWFS) }\end{array}$} & \multirow{2}{*}{ B-S1UB } & UPA & 3.5 & 12.05 & 46.60 \\
\hline & & TZBA & 5.0 & 17.24 & 40.60 \\
\hline & \multirow{2}{*}{ B-S2UB } & UPA & 2.8 & 9.66 & 40.87 \\
\hline & & TZBA & 2.0 & 6.90 & 34.82 \\
\hline
\end{tabular}

818

819 Table 1. Average values of diversity and abundance of microbial communities in the 820 two studied hydrostratigraphic units. Values obtained from analysis of DGGE profiles of

821 groundwater samples in multilevel wells S1UB and S2UB and PWFS in boreholes of

822 these multilevel wells.

823

$824 \quad 4.5 \quad$ Microorganisms involved in the degradation of CT and CF

825 4.5.1 Identification of OTU 6 and OTU 15 in the upper part of the aquifer

826 The combination of DGGE results with those of the clone library analysis (see Section

8273.2 and the SD) allowed identification of the band corresponding to A. suillum (OTU 6)

828 in the groundwater of all S1UB ports in the UPA (ports 1 to 4 , Figure 10A). This

829 indicates that $A$. suillum is a planktonic microorganism transported into the

830 groundwater flow (like many bacteria in the subsurface ecosystem, Herrmann et al.,

8312019 ) that probably comes from areas located upgradient of the DNAPL source, even

832 from beyond the petrochemical complex. By contrast, this band was only present in 
833 ports 2 and 4 in S2UB, although their abundance was similar in the two multilevel wells

834 (Figure 10A). OTU 6 was not identified in the DGGE profiles of PWFS in B-S1UB and

835 B-S2UB (in that case, in the fine matrix of interbedded sands collected at the UPA,

836 Figure 10C). The cause of this absence is the small portion of fine matrix in these

837 sands, which prevents the accumulation of this microorganism inside the matrix (see

838 below Section 4.5.2).

839 

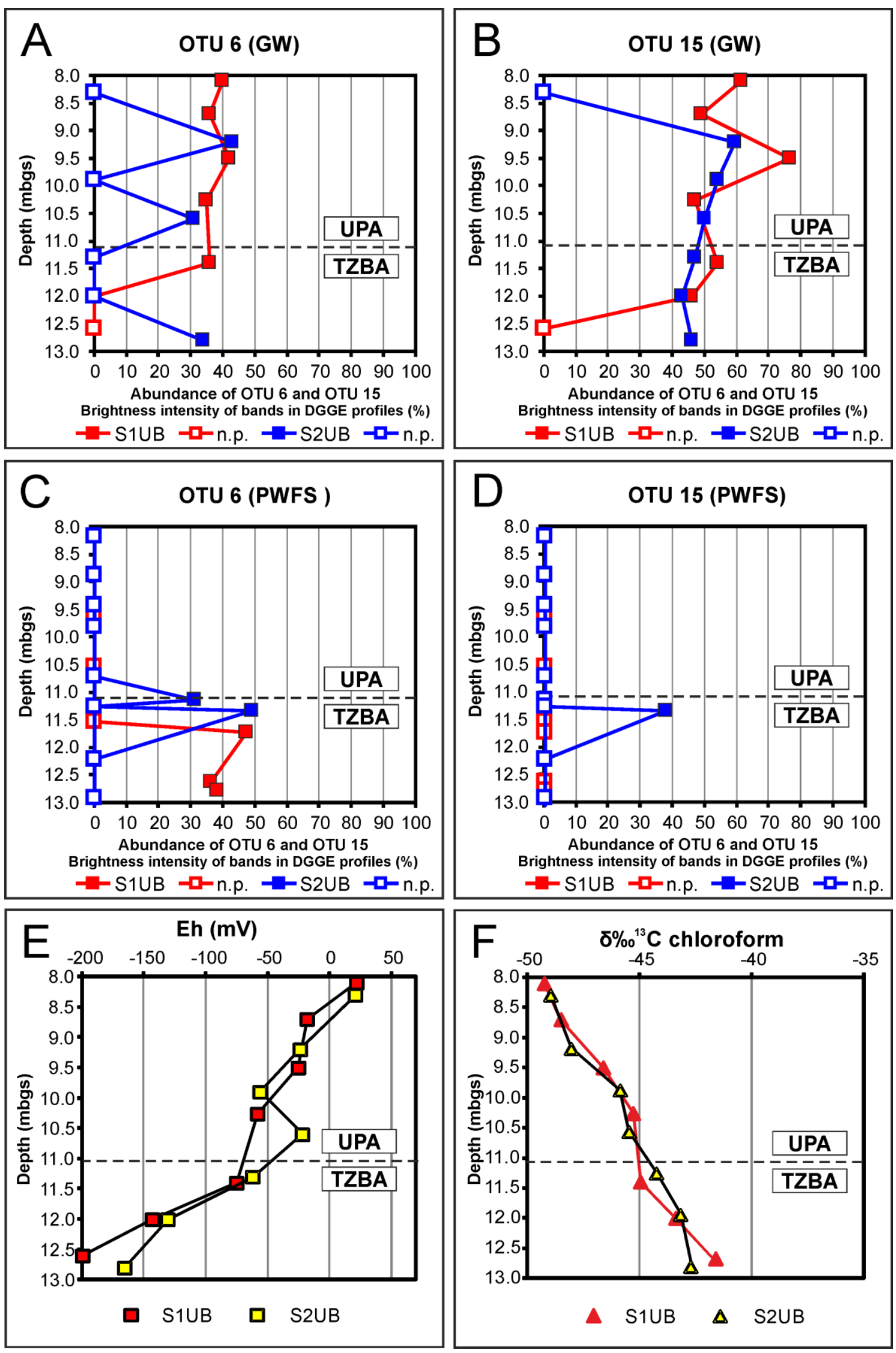

Figure 10. Abundance of OTU 6 (A. suillum) and OTU 15 (Clostridiales bacterium). (A) and $(B)$, in groundwater samples in multilevel wells. (C) and (D) in porewater of fine sediment samples. "np" = not presence of the microorganism. (E) and (F) Variation of Eh and isotopic composition of CF, respectively. 
846 The presence of OTU 6 in the groundwater of UPA (Figure 10A) coincided with the

847 following: (1) an increase of CT with depth (Figure 8A) due to the dissolution of the 848 secondary source of CT (see Section 4.2.2) and a decrease of the $\delta^{13} C_{\mathrm{CT}}$ value (Figure

$8498 \mathrm{C}$ ) due to the input of unfractionated CT from the secondary source; and (2) the 850 denitrification and sulfate-reduction processes with depth (Figure 6A; see Section 851 4.3.2). The presence of OTU 6 and the occurrence of denitrification agree with

852 Achenbach et al. (2001), who reported that $A$. suillum uses nitrate as an electron 853 acceptor.

854 As for the bacterium of the order Clostridiales (OTU 15) in the UPA, this microorganism 855 was present in all ports of S1UB in this hydrostratigraphic unit (ports 1 to 4 ) and in 856 almost all of S2UB (Figure 10B); hence, it is also a planktonic microorganism.

857 Moreover, OTU 15 presented greater abundance in the two multilevel wells than did 858 OTU 6 (Figure 10B). The presence of OTU 15 in the groundwater of this unit coincided 859 with: (1) an increase in the $\delta^{13} \mathrm{C}_{\mathrm{CF}}$ value (Figure 10F) and the presence of DCM (Figure 860 8D), which are elements supporting the reductive dechlorination of CF in the UPA; and 861 (2) the aforementioned denitrification process with depth (Figure 9A) under sulfate862 reducing dominant redox conditions (Figure 9B) with Eh values progressively more negative (Figure 10E). These findings agree with those of Grostern et al. (2010), Chan

864 et al. (2012), and Justicia-Leon et al. (2014), who reported that the Clostridiales order

865 of bacteria includes the genus Dehalobacter, which gives rise to reductive

866 dechlorination of CF (and isotopic fractionation of this compound) to form DCM.

867 Furthermore, Justicia-Leon et al. (2014) demonstrated that the biodegradation of CF to 868 DCM occurs under anoxic conditions, including those of denitrification. Similar to the 869 case of OTU 6, OTU 15 was not identified in the sediment samples collected in the 870 UPA in B-S1UB and B-S2UB. Furthermore, it was only present in one sample in the 871 TZBA (Figure 10D), which indicates that, unlike $A$. suillum, the ability to penetrate the 
872 fine materials of the Clostridiales microorganism was hindered, probably because of a

873 .cell size larger than the pore throat threshold diameter value of $0.9 \mu \mathrm{m}$ (see Section

874 4.4).

875 4.5.2 Role of OTU 6 and OTU 15 in degrading CT and CF in the transition zone

876 The band corresponding to A. suillum (OTU 6) was only identified in port 5 of S1UB

877 and port 7 of S2UB in the groundwater at the TZBA (Figure 10A), which again shows

878 that $A$. suillum is a planktonic microorganism (see Section 4.5.1). In contrast, this band

879 was identified at several depths in the DGGE profiles of PWFS in this unit (Figure 10C)

880 and with a greater abundance than that in groundwater ports 5 of S1UB and 7 of S2UB

881 (Figure 10A), which is evidence that the cell size of $A$. suillum is small enough to

882 penetrate into the finest sediments (see Section 4.4¡Error! No se encuentra el origen

883 de la referencia.), where it accumulates and remains attached to the surface of

884 mineral grains. This microorganism is an anaerobic, nitrate-dependent bacterium that

885 rapidly uses the Fe(II) content of natural sediments as an electron donor under anoxic

886 conditions and nitrate as the electron acceptor (Achenbach et al., 2001) to produce

887 mixed-valence $\mathrm{Fe}(\mathrm{II})-\mathrm{Fe}(\mathrm{III})$ byproduct precipitates, which are unstable iron minerals

888 that correspond to green rusts (Chaudhuri et al., 2001; Lack et al., 2002; Weber et al.,

889 2006; Nam et al.; 2016). Studies by different authors have confirmed the abiotic

890 reductive dechlorination process of CT in the presence of green rusts (Liang and

891 Butler, 2010; Yin et al., 2017), which are common natural electron donors in aquifers

892 (Matocha, Dhakal and Pyzola, 2012) capable of degrading CT to CF, DCM, CM, and

$893 \mathrm{CH}_{4}(\mathrm{O}$ 'Loughlin, Kemner and Burris, 2003). Although the occurrence of green rusts

894 was not determined in the present study, the following indirect indications that suggest

895 their occurrence and role as natural reducing agents of CT to form CF were confirmed

896 in the TZBA: (1) A. suillum was present, especially in the PWFS of the TZBA (with an

897 abundance greater than that in the UPA, Figure 10C); (2) the very high denitrification

898 rate and enrichment factor ( $\lambda$ and $\varepsilon$ values of $0.0069 \mathrm{~m}^{-1}$ and $-19.91 \%$, respectively) 
and the Fe-reduction of iron oxidized minerals, which delivers $\mathrm{Fe}^{2+}$ to the environment

900 (Figure 7G); (3) the decrease of CT in groundwater (Figure 8;Error! No se encuentra

901 el origen de la referencia.A, from ports 5 to 7 ) and in the fine sediments (data shown

902 in Puigserver et al., 2013); (4) the high values in the attenuation rate and enrichment

903 factor of CT in the TZBA ( $\lambda$ and $\varepsilon$ of $0.0044 \mathrm{~m}^{-1}$ and $-3.42 \%$, respectively), which

904 contrast with those of CT in the UPA $\left(0.0029 \mathrm{~m}^{-1}\right.$ and $\left.-0.81 \%\right)$; (5) the increase of CF in

905 groundwater in ports of the two multilevel wells at the TZBA (Figure 8;Error! No se

906 encuentra el origen de la referencia.B) and in fine sediments at a similar depth to

907 that of ports 6 and 7 of this unit (Puigserver et al., 2013); (6) the high rate of sulfate-

908 reduction and enrichment factor ( $\lambda$ and $\varepsilon$ of $0.0085 \mathrm{~m}^{-1}$ and $-17.10 \%$, respectively); and

909 (7) the dominant sulfate-reducing redox conditions (Figure 9B) and highly anoxic

910 environment at the TZBA (Figure 10E) as a consequence of the intrinsically high

911 geological and textural heterogeneity in this hydrostratigraphic unit (see Section 4.3.1).

912 All these indications are consistent with the precipitation of green rusts that are

913 biogenically formed by $A$. suillum, and the subsequent abiotic reductive dechlorination

914 of CT by the green rust. Thus, the reductive dechlorination of CT observed in the TZBA

915 would correspond to an abiotic process that was biogenically mediated by $A$. suillum.

916 With respect to the bacterium of the order Clostridiales in the TZBA, it is reasonable to

917 refer again to the genus Dehalobacter mentioned in Section 4.5.1. In this section, the

918 authors reported that Dehalobacter is a genus of the order Clostridiales capable of

919 giving rise to reductive dechlorination of CF, accompanied by isotopic fractionation, to

920 form DCM. This finding agrees with the laboratory-scale observations of Puigserver et

921 al. (2016c) and with the field-scale observations of the present study, in which a

922 bacterium of the order Clostridiales was involved in the biotic reductive dechlorination

923 of CF to form DCM and CM (Figure 8D).jError! No se encuentra el origen de la

924 referencia.

925 4.6 Key control of heterogeneity in the TZBA on the NA of CT and CF 
926 A sequence of successively dependent factors representing the conceptual model of

927 the fate of CT and CF in the TZBA (Figure 11) reveals that the high geological and

928 textural heterogeneity in the TZBA compared to the homogeneity in the UPA is the

929 most important key control exerted on the greater efficiency of the NA of CT and CF in

930 the TZBA than in the UPA.

931

932

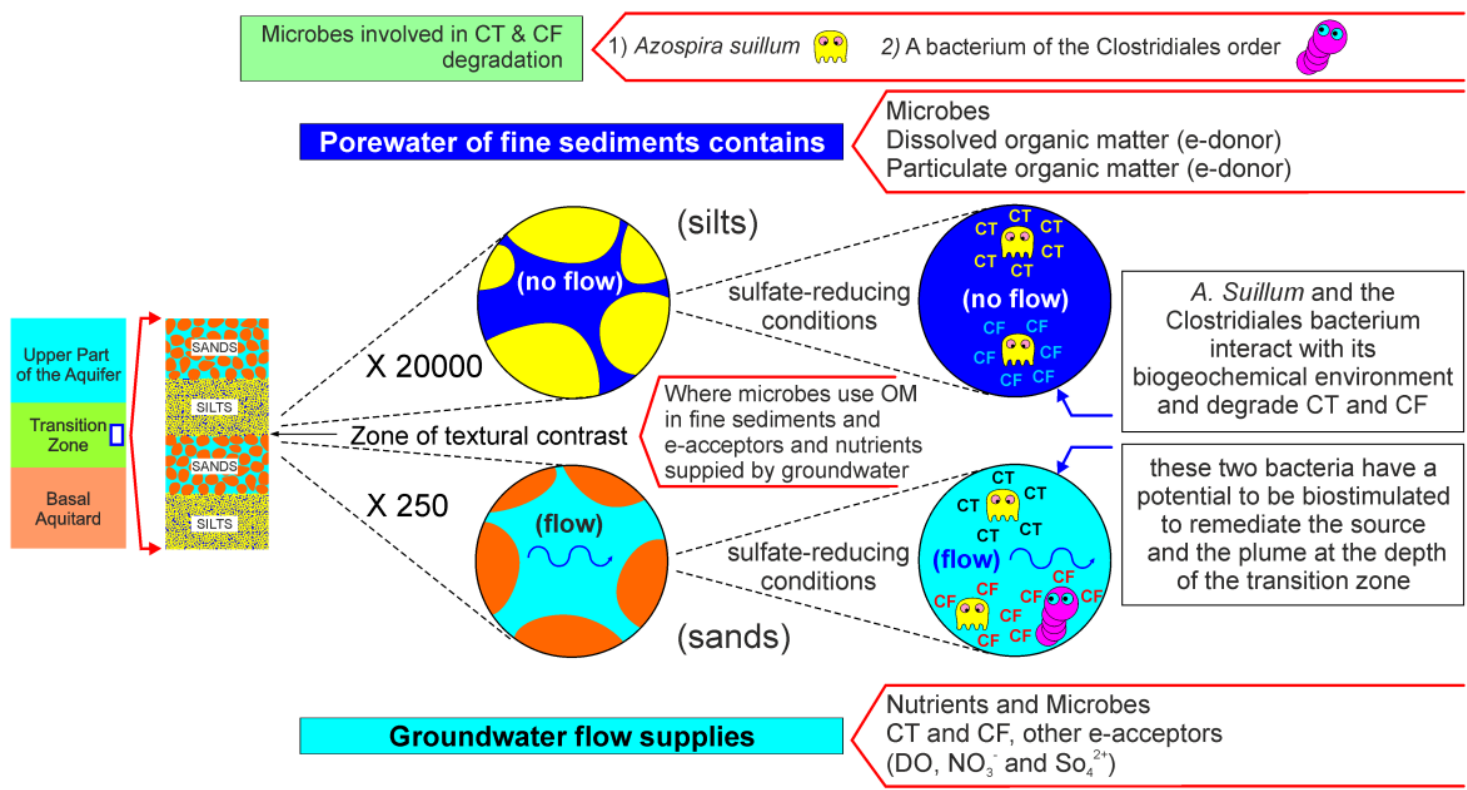

933 Figure 11. Conceptual model that represents how $A$. suillum and the Clostridiales

934 bacterium interact with the biogeochemical environment.

935

936 The high geological heterogeneity in the TZBA, with the presence of numerous

937 interbedded layers of silty-clays, sands, and gravels with variable fine matrix content in

938 this unit (see Section 4.1), accounts for the high textural heterogeneity observed, with

939 abundant textural contrasts between fine and coarse materials. These contrasts result

940 in hydraulic conductivity differences between adjacent layers (Figure 2B), which for the

941 whole TZBA derive in a low hydraulic conductivity and transmissivity (much lower than

942 those in the UPA, see Section 4.1). 
943 According to Goldscheider et al. (2006), contact surfaces between different texture

944 materials become ecotones (a zone where exchanges among two adjacent microbial

945 ecosystems occur, see Section 4.4). Since the TZBA constitutes a succession of

946 numerous texture changes, it can be agreed that this zone as a whole is an ecotone

947 product of the high geological and textural heterogeneity.

948 Given the low transmissivity in the TZBA, DO supplied to the source and the plume by

949 groundwater flowing through the coarser grain size layers is little (especially at the

950 source, where much of the pores are partially occupied by DNAPL, see Section 4.3.1).

951 In addition to DO, other compounds and elements are provided by groundwater flow: i)

952 more electron acceptors (nitrate, sulfate, CT, CF, and their metabolites), ii) electron

953 donors (such as dissolved organic matter), and iii) nutrients and other components

954 needed by microbes living in groundwater and in the fine grained less-conductive

955 layers, where a large favorable substrate of dissolved and particulate organic matter

956 exists (Naganna, Deka, and Hansen, 2017) acting as carbon and energy sources for

957 microorganisms. The large amount of organic carbon acting as an electron donor

958 causes the small amount of DO that reaches the source and plume to be consumed.

959 This demonstrates the role played by the geological and textural heterogeneity in the

960 development of suitable conditions for the NA of CT and CF, since the consumption of

961 the supplied DO gives rise to a highly anoxic environment (see Sections 4.2.1 and

962 4.3.1) under which the dominant redox conditions become sulfate-reducing (see

963 Sections 4.2.2 and 4.3.2).

964 These redox conditions, along with components supplied by groundwater and organic

965 matter substrate in the fine material layers, are suitable for $A$. suillum and the

966 bacterium of the order Clostridiales to give rise to the natural reductive dechlorination

967 of CT and CF (and metabolites). They are planktonic microorganisms transported with

968 groundwater (see Section 4.5.1) along the levels of coarse materials in the TZBA. $A$.

969 suillum is small enough to penetrate the finest materials, while the larger cell size of the 
970 Clostridiales bacterium hinders its ability to penetrate those finer materials (see Section

971 4.5.2). Therefore, geological and textural heterogeneity also control the subsurface

972 distribution of microorganisms that degrade CT and CF.

\section{$973 \quad$ 5. Conclusions}

974 The most important key control exerted on the greater efficiency of natural attenuation

975 of CT and CF in the TZBA than in the UPA is the high geological and textural

976 heterogeneity in the transition zone, resulting from the numerous interbedded silty-clay

977 layers between fine to coarse sands and gravels with variable fine matrix content.

978 This geological and textural heterogeneity is responsible for the highly anoxic

979 environment under sulfate-reducing dominant redox conditions at the source and the

980 plume. The following factors give rise to the development of conditions suitable for

981 degradation of CT and CF: i) low hydraulic conductivity and transmissivity, which

982 implies a small DO supply with groundwater flow through the coarser grain size layers,

983 and ii) consumption of what little remains of the DO by the high amount of dissolved

984 and particulate organic matter in the finer grain size layers, acting as a carbon and

985 energy source for microorganisms.

986 As a consequence of the geological and textural heterogeneity, the transition zone

987 constitutes an ecotone, which conditions the diversity and abundance of the microbial

988 ecosystem. Moreover, the pore throat threshold is one of the textural parameters of the

989 of subsurface sediments, and is, therefore, also determined by the geological and

990 textural heterogeneity in the transition zone. This parameter also controls the

991 subsurface distribution of microorganisms, since bacteria size exclusion causes a

992 decrease in the diversity and abundance of microbial communities. Thus, the bacterium

993 of the order Clostridiales, which is a planktonic microorganism that migrates with the

994 groundwater flow and performs the reductive dechlorination of CF to DCM in the

995 coarse and more-conductive materials, is unable to penetrate the finest materials in the

996 transition zone, probably because its cell size is larger than the pore throat threshold 
997 value. By contrast, $A$. suillum, which is also a planktonic microorganism involved in the

998 reductive dechlorination of CT and CF in groundwater, is able to enter into the finer and

999 less-conductive materials because its cell size is less than the pore throat threshold.

1000 Once inside the PWFS, A. suillum accumulates and remains attached to the surface of

1001 mineral grains (which accounts for its great abundance in fine materials), where it is

1002 implicated in the degradation of the CT and CF that penetrated via molecular diffusion

1003 from the more-conductive materials.

1004 Bacteria size exclusion determines, therefore, the penetration of dechlorinating

1005 microorganisms into the finest and less-conductive materials and should be an

1006 important issue to consider for any contamination scenario in which bioremediation

1007 strategies such as biostimulation or bioaugmentation are proposed. These strategies

1008 may be ineffective if a significant part of the microorganisms involved cannot enter into

1009 the finest contaminated sediments. The relevance of this lies in the need to verify

1010 whether the microorganisms involved can physically migrate through the finest

1011 sediments before implementing the remediation strategies.

1012 The natural attenuation of CT observed in the transition zone is an abiotic reductive

1013 dechlorination process in the presence of green rusts biogenically generated by $A$.

1014 suillum. Different evidence indicates the generation of green rusts precipitates as a

1015 byproduct of the biogenic activity of $A$. suillum and the role of these Fe-minerals as

1016 natural reducing agents of CT to form CF, DCM, and CM (and possibly $\mathrm{CH}_{4}$ ) in the

1017 transition zone. These proofs indicate that the necessary conditions exist in this zone

1018 for $A$. suillum to give rise to green rusts using the $\mathrm{Fe}(\mathrm{II})$ content of sediments as

1019 electron donors and nitrates as electron acceptors under anoxic conditions: a) the

1020 greater abundance of $A$. suillum in the transition zone than in the upper part of the

1021 aquifer; b) the dominant sulfate-reducing redox conditions and highly anoxic

1022 environment at the transition zone; c) the Fe-reduction of iron oxidized minerals, which

1023 delivers $\mathrm{Fe}^{2+}$ to the environment; and d) a high denitrification rate and enrichment 
1024 factor for ${ }^{15} \mathrm{~N}$. This evidence also shows that the formation of green rusts in the

1025 transition zone is also a consequence of the intrinsically high geological and textural

1026 heterogeneity in this hydrostratigraphic unit.

1027 Given the favorable conditions for natural attenuation of CT and CF in the transition

1028 zone, A. suillum and the Clostridiales bacterium have a potential to be biostimulated to

1029 promote the remediation of CT and CF in the source and the plume in this

1030 hydrostratigraphic unit.

1031 Two important questions are derived from the present study that should be answered

1032 when designing aquifer biostimulation or bioaugmentation schemes: (1) Which

1033 indigenous microorganisms are involved in the natural attenuation of contaminants? (2)

1034 Under which dominant redox conditions are these microorganisms more efficient? (3)

1035 In the case of fine materials into which pollutants penetrate by molecular diffusion, is

1036 the size of their cells greater than the threshold value? In this case, it would be possible

1037 to combine biostimulation and bioaugmentation schemes to avoid the rebound effect.

1038 This information is of particular relevance in cases in which a DNAPL source in the

1039 aquifer is in a transition zone (given the longevity of the sources in these cases). These

1040 factors have important environmental implications for two reasons: (1) many supply

1041 wells exploit aquifers in basins in which land uses are devoted to industries related to

1042 the frequent use or handling of chlorinated solvents and (2) from the geological point of

1043 view, these basins are frequently filled with clastic sediments that constitute alluvial fan

1044 deposits and sheet floods that correspond to transition zones with numerous fine-

1045 grained layers above which DNAPL pools accumulate.

\section{Acknowledgments}

1048 We are indebted to the Catalan Water Agency and members of the company Clariant

1049 Ibérica S.A. of Tarragona for the support and cooperation while carrying out the field 
1050 work. We would also like to thank the members of the Scientific and Technological

1051 Centers of the University of Barcelona. At the same time, we would like to acknowledge

1052 the institutions that financed the research within the following research projects: CTM 1053 2005-07824 and CGL 2008-02164/BTE funded by the Spanish Ministry of Education 1054 and Science and Clariant lbérica S.A.

1055

\section{References}

1057 Achenbach, L.A.; Michaelidou, U.; Bruce, R.A.; Fryman, J. and Coates, J.D. (2001).

1058 Dechloromonas agitata gen. nov., sp. nov. and Dechlorosoma suillum gen. nov., sp.

1059 nov., two novel environmentally dominant (per)chlorate-reducing bacteria and their

1060 phylogenetic position. International Journal of Systematic and Evolutionary

1061 Microbiology, 51:527-533. http://dx.doi:10.1099/00207713-51-2-527

1062 Alexander, M. (1978). Introduction to soil microbiology. Soil Science, 125(5):331.

1063 Alvarez, L.H.; Jimenez-Bermudez, L.; Hernandez-Montoya, V. and Cervantes, F.J.

1064 (2012). Enhanced dechlorination of carbon tetrachloride by immobilized fulvic acids on

1065 alumina particles. Water, Air, and Soil Pollution, 223(4):1911-1920.

1066 Amodu, O.S.; Ojumu; T.V. and Ntwampel, S.K.O. (2013). Bioavailability of high

1067 molecular weight polycyclic aromatic hydrocarbons using renewable resources. In

1068 Environmental Biotechnology-New Approaches and Prospective Applications. Intech

1069 (chapter 8). Environmental Biotechnology - New Approaches and Prospective

1070 Applications. http://dx.doi.org/10.5772/54727.

1071 Assaf-Anid, N. and Lin, K.Y. (2002). Carbon tetrachloride reduction by $\mathrm{Fe}^{2+}, \mathrm{S}^{2-}$, and

1072 FeS with vitamin $B_{12}$ as organic amendment. Journal of environmental engineering,

1073 128(1):94-99.

1074 Bouwer, E.J. (1994). Bioremediation of chlorinated solvents using alternate electron 1075 acceptors. In: Matthews, J.E. (Ed.), Handbook of Bioremediation. Lewis Publishers, 1076 London, pp. 149-175.

1077 Chan, C.C.; Mundle, S.O.; T. Eckert, X. Liang, S. Tang, G. Lacrampe-Couloume, E.A. 1078 Edwards and B. Sherwood Lollar (2012). Large carbon isotope fractionation during 
1079 biodegradation of chloroform by Dehalobacter cultures. Environmental science \&

1080 technology. 46:10154-10160.

1081 Chaudhuri, S.K.; Lack, J.G. and Coates, J.D. (2001). Biogenic Magnetite Formation

1082 through Anaerobic Biooxidation of Fe (II). Applied and Environmental Microbiology,

1083 67(6):2844-2848. doi: 10.1128/AEM.67.6.2844-2848.

1084 Christensen, T.H.; Bjerg, P.L.; Banwart, S.A.; Jakobsen, R.; Heron, G. and

1085 Albrechtsen, H.J. (2000). Characterization of redox conditions in groundwater

1086 contaminant plumes. Journal of Contaminant Hydrology, 45(3-4):165-241.

1087 Cohen, R.M. and Mercer, J.W. (1993). DNAPL Site Investigation. C.K. Smoley, Boca 1088 Raton, USA.

1089 Cycoń, M.; Markowicz, A.; Borymski, S.; Wójcik, M. and Piotrowska-Seget, Z. (2013).

1090 Imidacloprid induces changes in the structure, genetic diversity and catabolic activity of

1091 soil microbial communities. Journal of environmental management, 131:55-65.

1092 Da Lima, G.P. and Sleep, B.E. (2010). The impact of carbon tetrachloride on an 1093 anaerobic methanol-degrading microbial community. Water, Air, and Soil Pollution, 1094 212(1-4):357-368.

1095 Davis, A.; Fennemore, G.G; Peck, C.; Walker, C.R.; Mcllwraith, J. and Thomas, S. 1096 (2003). Degradation of carbon tetrachloride in a reducing groundwater environment:

1097 Implications for natural attenuation. Applied Geochemistry, 18:503-525.

1098 Dogramaci, S.S.; Herczeg, A.L.; Schiff, S.L.; Bone, Y. (2001). Controls on $\delta^{34}$ S and $1099 \delta^{18} \mathrm{O}$ of dissolved $\mathrm{SO}_{4}$ in aquifers of the Murray Basin, Australia and their use as 1100 indicators of flow processes. Applied Geochemistry, 16:475-488.

1101 Einarson, M., Fure, A., St. Germain, R., Chapman, S. and Parker, B. (2018). DyeLIF TM :

1102 A New Direct-Push Laser-Induced Fluorescence Sensor System for Chlorinated

1103 Solvent DNAPL and Other Non-Naturally Fluorescing NAPLs. Groundwater Monitoring

1104 \& Remediation, 38(3):28-42.

1105 Farthing, M.W.; Seyedabbasi, M.A.; Imhoff, P.T. and Miller, C.T. (2012). Influence of 1106 porous media heterogeneity on nonaqueous phase liquid dissolution fingering and 1107 upscaled mass transfer. Water Resources Research, 48(W08507).

1108 doi:10.1029/2011WR011389. 
1109 Fetter, C.W.; Boving, T.; and Kreamer, D. (2017). Contaminant hydrogeology.

1110 Waveland Press.

1111 Fjordbøge, A.S.; Janniche, G.S.; Jørgensen, T.H.; Grosen, B.; Wealthall, G.;

1112 Christensen, A.G.; Kerrn-Jespersen, H. and Broholm, M. M. (2017). Integrity of clay till

1113 aquitards to DNAPL migration: Assessment using current and emerging

1114 characterization tools. Groundwater Monitoring \& Remediation, 37(3):45-61.

1115 Fraser, P.J.; Dunse, B.L.; Manning, A.J.; Walsh, S.; Wang, R.H.J.; Krummel, P.B. and

1116 Simmonds, P.G. (2014). Australian carbon tetrachloride emissions in a global context.

1117 Environmental Chemistry, 11(1):77-88.

1118 Fukada, T.; Hiscock, K.M.; Dennis, P.F.; Grischek, T. (2003). A dual isotope approach

1119 to identify denitrification in groundwater at a river bank infiltration site. Water Research,

$1120 \quad 37: 3070-3078$

1121 Goldscheider, N.; Hunkeler, D. and Rossi, P. (2006). Review: microbial biocenoses in

1122 pristine aquifers and an assessment of investigative methods. Hydrogeology Journal,

1123 14(6):926-941.

1124 Grostern, A.; Duhamel, M.; Dworatzek, S. and Edwards, E.A. (2010). Chloroform

1125 respiration to dichloromethane by a Dehalobacter population. Environmental

1126 microbiology, 12(4):1053-1060.

1127 Hartog H.; Cho J.; Parker B.L.; Annable, M.D. (2010) Characterization of a

1128 heterogeneous DNAPL source zone in the Borden aquifer using partitioning and

1129 interfacial tracers: residual morphologies and background sorption. J Contam Hydrol

1130 115(1):79-89.

1131 Herrmann, M., Wegner, C. E., Taubert, M., Geesink, P., Lehmann, K., Yan, L.

1132 Lehmann, R. and Küsel, K. (2019). Predominance of Cand. Patescibacteria in

1133 groundwater is caused by their preferential mobilization from soils and flourishing under

1134 oligotrophic conditions. Frontiers in Microbiology, 10, 1407.

1135 Hunkeler, D., Meckenstock, R.U., Sherwood Lollar, B., Schmidt, T.C., Wilson, J.T., 1136 Schmidt, T. and Wilson, J. (2008). A guide for assessing biodegradation and source

1137 identification of organic ground water contaminants using compound specific isotope 1138 analysis (CSIA). Oklahoma, USA, US EPA. 
1139 Hunkeler, D.; Abe, Y.; Broholm, M.M.; Jeannottat, S.; Westergaard, C.; Jacobsen, C.S.

1140 and Bjerg, P.L. (2011). Assessing chlorinated ethene degradation in a large scale

1141 contaminant plume by dual carbon-chlorine isotope analysis and quantitative PCR.

1142 Journal of contaminant hydrology, 119(1):69-79.

1143 Imhoff, P.T.; Jaffe, P.R. and Pinder G.F. (1994), An experimental study of complete

1144 dissolution of a nonaqueous phase liquid in saturated porous media. Water Resources

1145 Research, 30(2):307-320. https://doi.org/10.1029/93WR02675.

1146 ITRC (Interstate Technology \& Regulatory Council). (2015). Integrated DNAPL Site

1147 Characterization and Tools Selection (ISC-1).

1148 Joergensen, R.G. and Wichern, F. (2018). Alive and kicking: Why dormant soil

1149 microorganisms matter. Soil Biology and Biochemistry, 116:419-430.

1150 Johnston, D. (2006). Draft EPA Guidelines Regulatory Monitoring and Testing

1151 Groundwater Sampling 56. Environment Protection authority (EPA), Australia.

1152 Justicia-Leon, S.D.; Higgins, S.; Mack, E.E.; Griffiths, D.R.; Tang, S.; Edwards, E.A.

1153 and Löffler, F.E. (2014). Bioaugmentation with distinct Dehalobacter strains achieves

1154 chloroform detoxification in microcosms. Environmental science \& technology,

1155 48(3):1851-1858.

1156 Lack, J.G.; Chaudhuri, S.K.; Chakraborty, R.; Achenbach, L.A. and Coates, J.D.

1157 (2002). Anaerobic biooxidation of Fe (II) by Dechlorosoma suillum. Microbial ecology,

1158 43(4):424-431.

1159 Liang, X. and Butler, E.C. (2010). Effects of natural organic matter model compounds

1160 on the transformation of carbon tetrachloride by chloride green rust. Water Research,

1161 44(7):2125-2132.

1162 Luciano, A.; Viotti, P. and Papini, M.P. (2010). Laboratory investigation of DNAPL

1163 migration in porous media. Journal of Hazardous Materials, 176(1):1006-1017.

1164 Mackay, D.M. and Cherry, J.A. (1989). Groundwater contamination: pump-and treat

1165 remediation. Environmental Science and Technology 23, 630-636.

1166 Matocha, C.J.; Dhakal, P. and Pyzola, S.M. (2012). The role of abiotic and coupled 1167 biotic/abiotic mineral controlled redox processes in nitrate reduction. In Advances in 1168 agronomy (Vol. 115, pp. 181-214). Academic Press. 
1169 Muyzer, G.; De Waal, E.C. and Uitterlinden, A.G. (1993). Profiling of complex microbial

1170 populations by denaturing gradient gel electrophoresis analysis of polymerase chain

1171 reaction-amplified genes coding for 16S rRNA. Applied and Environmental

1172 Microbiology, 59(3):695-700.

1173 Naganna, S. R., Deka, P. C., Ch, S. and Hansen, W. F. (2017). Factors influencing

1174 streambed hydraulic conductivity and their implications on stream-aquifer interaction: a

1175 conceptual review. Environmental Science and Pollution Research, 24(32), 24765-

117624789.

1177 Nam, J.H.; Ventura, J.R.S.; Yeom, I.T.; Lee, Y. and Jahng, D. (2016). A novel

1178 perchlorate-and nitrate-reducing bacterium, Azospira. Applied microbiology and

1179 biotechnology, 100(13):6055-6068.

1180 O'Loughlin, E.J.; Kemner, K.M. and Burris, D.R. (2003). Effects of Ag, Au and Cu on

1181 the reductive dechlorination of carbon tetrachloride by green rust. Environmental

1182 Science \& Technology. 37:2905-2912.

1183 Palau, J.; Soler, A.; Teixidor, P. and Aravena, R. (2007). Compound-specific carbon

1184 isotope analysis of volatile organic compounds in water using solid-phase

1185 microextraction. Journal of Chromatography A, 1163:260-268.

1186 Pankow, J.F.; Cherry, J.A. (1996). Dense Chlorinated Solvents and other DNAPL's in

1187 Groundwater: History, Behavior, and Remediation. Waterloo Press, Portland, Oreg.

1188 U.S.A.

1189 Parker, B.L.; Chapman, S.W.; and Guilbeault, M.A. (2008). Plume persistence caused

1190 by back diffusion from thin clay layers in a sand aquifer following TCE source-zone

1191 hydraulic isolation. Journal of Contaminant Hydrology, 102:86-104.

1192 Parker, B.L.; Cherry, J.A. and Chapman, S.W. (2004). Field study of TCE diffusion

1193 profiles below DNAPL to assess aquitard integrity. Journal of Contaminant Hydrology,

1194 74(1):197-230.

1195 Parker, B.L.; Cherry, J.A.; Chapman, S.W. and Guilbeault, M.A. (2003). Review and

1196 analysis of chlorinated solvent dense nonaqueous phase liquid distributions in five

1197 sandy aquifers. Vadose Zone Journal, 2:116-137. 
1198 Penny, C.; Gruffaz, C.; Nadalig, T.; Cauchie, H.M.; Vuilleumier, S. and Bringel, F.

1199 (2015). Tetrachloromethane-degrading bacterial enrichment cultures and isolates from

1200 a contaminated aquifer. Microorganisms, 3(3):327-343.

1201 Penny, C.; Vuilleumier, S. and Bringel, F. (2010). Microbial degradation of

1202 tetrachloromethane: mechanisms and perspectives for bioremediation. FEMS

1203 microbiology ecology, 74(2):257-275.

1204 Portillo, M. C., Leff, J. W., Lauber, C. L. and Fierer, N. (2013). Cell size distributions of

1205 soil bacterial and archaeal taxa. Applied and environmental microbiology, AEM-02710.

1206 Puigserver, D.; Carmona, J.M.; Cortés, A.; Viladevall, M.; Nieto, J.M.; Grifoll, M. and

1207 Parker, B.L. (2013). Subsoil heterogeneities controlling porewater contaminant mass

1208 and microbial diversity at a site with a complex pollution history. Journal of contaminant

1209 hydrology, 144(1):1-19.

1210 Puigserver, D.; Cortés, A.; Viladevall, M.; Nogueras, X.; Parker, B.L. and Carmona,

1211 J.M. (2014). Processes controlling the fate of chloroethenes emanating from DNAPL

1212 aged sources in river-aquifer contexts. Journal of contaminant hydrology, 168:25-40.

1213 Puigserver, D.; Herrero, J.; Torres, M.; Cortés, A.; Nijenhuis, I.; Kuntze, K. and

1214 Carmona, J.M. (2016a). Reductive dechlorination in recalcitrant sources of

1215 chloroethenes in the transition zone between aquifers and aquitards. Environmental

1216 Science \& Pollution Research, 23(18):18724-18741.

1217 Puigserver, D.; Herrero, J.; Torres, M.; Cortés, A.; Nijenhuis, I.; Kuntze, K. and

1218 Carmona, J.M. (2016b). Degradation of chloroethenes in the transition zone between

1219 aquifers and aquitards. WIT Transactions on Ecology and the Environment. 209:115-

1220126.

1221 Puigserver, D.; Nieto, J.M.; Grifoll, M.; Vila, J.; Cortés, A.; Viladevall, M. and Carmona, 1222 J.M. (2016c). Temporal hydrochemical and microbial variations in microcosm

1223 experiments from sites contaminated with chloromethanes under biostimulation with

1224 lactic acid. Bioremediation Journal. 20(1):54-70.

1225 Puls, R.W.; Barcelona, M.J. (1996). Low-flow (minimal drawdown) ground-water 1226 sampling procedures. Ground Water Issue 12. EPA. 
1227 Ramsburg, C.A.; Thornton, C.E. and Christ, J.A. (2010). Degradation product

1228 partitioning in source zones containing chlorinated ethene dense non-aqueous-phase

1229 liquid. Environmental science \& technology, 44(23):9105-9111.

1230 Rivett, M. O., Dearden, R. A. and Wealthall, G. P. (2014). Architecture, persistence and

1231 dissolution of a 20 to 45 year old trichloroethene DNAPL source zone. Journal of

1232 contaminant hydrology, 170:95-115.

1233 Rotiroti, M.; Jakobsen, R.; Fumagalli, L. and Bonomi, T. (2018). Considering a

1234 threshold energy in reactive transport modeling of microbially mediated redox reactions

1235 in an arsenic-affected aquifer. Water, 10(1):90.

1236 Shuangfang, L.U., Junqian, L.I., ZHANG, P., Haitao, X U.E., Guoli, W.A.N.G., ZHANG,

1237 J. and Zheng, L.I. (2018). Classification of microscopic pore-throats and the grading

1238 evaluation on shale oil reservoirs. Petroleum Exploration and Development, 45(3):452-

1239460.

1240 Silva, S.R.; Kendall, C.; Wilkinson, D.H.; Ziegler, A.C.; Chang, C.C.Y.; Avanzino, R.J.

1241 (2000). A new method for collection of nitrate from fresh water and the analysis of

1242 nitrogen and oxygen isotope ratios. Journal of Hydrology, 228:22-36.

1243 Trevors, J.T. (1996). Sterilization and inhibition of microbial activity in soil. Journal of

1244 Microbiological Methods, 26:53-59.

1245 US Environmental Protection Agency (2008). A guide for assessing biodegradation and

1246 source identification of organic ground water contaminants using compound specific

1247 isotope analysis (CSIA). Ada, OK: Office of Research and Development, US

1248 Environmental Protection Agency.

1249 Vickstrom, K.E.; Azizian, M.F. and Semprini, L. (2017). Transformation of carbon

1250 tetrachloride and chloroform by trichloroethene respiring anaerobic mixed cultures and

1251 supernatant. Chemosphere, 182:65-75.

1252 Vikesland, P.J.; Heathcock, A.M.; Rebodos, R.L. and Makus, K.E. (2007). Particle size

1253 and aggregation effects on magnetite reactivity toward carbon tetrachloride.

1254 Environmental science \& technology, 41(15):5277-5283.

1255 Wanner, P.; Parker, B.L.; Chapman, S.W.; Aravena, R. and Hunkeler, D. (2016).

1256 Quantification of Degradation of Chlorinated Hydrocarbons in Saturated Low 
1257 Permeability Sediments Using Compound-Specific Isotope Analysis. Environmental

1258 science \& technology, 50(11):5622-5630.

1259 Weatherill, J. J.; Atashgahi, S.; Schneidewind, U.; Krause, S.; Ullah, S.; Cassidy, N.;

1260 and Rivett, M.O. (2018). Natural attenuation of chlorinated ethenes in hyporheic zones:

1261 a review of key biogeochemical processes and in-situ transformation potential. Water

1262 research, 128:362-382.

1263 Weber, K.A.; Achenbach, L.A. and Coates, J.D. (2006). Microorganisms pumping iron:

1264 anaerobic microbial iron oxidation and reduction. Nature Reviews Microbiology,

$12654(10): 752-764$.

1266 Xiao, X.; Prinn, R.G.; Fraser, P.J.; Weiss, R.F.; Simmonds, P.G.; O'Doherty, S. and

1267 Golombek, A. (2010). Atmospheric three-dimensional inverse modeling of regional

1268 industrial emissions and global oceanic uptake of carbon tetrachloride. Atmospheric

1269 Chemistry and Physics, 10(21):10421-10434.

1270 Yin, W., Strobel, B.W. and B. Hansen, H.C. (2017). Amino Acid-Assisted

1271 Dehalogenation of Carbon Tetrachloride by Green Rust: Inhibition of Chloroform

1272 Production. Environmental Science \& Technology, 51(6):3445-3452.

1273

1274 